\title{
Turbulence underneath the big calm? The micro-evidence behind Italian productivity dynamics
}

\author{
Giovanni Dosi • Marco Grazzi · Chiara Tomasi • \\ Alessandro Zeli
}

Accepted: 7 March 2011/Published online: 7 April 2011

(C) Springer Science+Business Media, LLC. 2011

\begin{abstract}
Italy ranked last in terms of manufacturing productivity growth according to OECD estimates over the last decade, with a flat, if not declining, trend. In this work we investigate the underlying firm-level dynamics of enterprises on the basis of a database developed by the Italian Statistical Office (ISTAT) covering the period 1989-2004 and containing information on more than 100,000 firms. Over this period not only have the indicators of the central tendency of the distribution of labor productivity not significantly changed, but also the whole sectoral distributions have remained relatively stable over time, with their support at least not shrinking, or even possibly widening, over time. This is even more surprising if one takes into consideration the "Euro" shock that occurred during the period investigated. On the contrary, we observe that inter-decile differences in productivity have been increasing. Further, heterogeneous firms' characteristics (i.e. export activity and innovation) seem to have contributed to
\end{abstract}

G. Dosi · M. Grazzi $(\bowtie) \cdot$ C. Tomasi

LEM, Scuola Superiore Sant'Anna, Piazza Martiri della Libertà, 33, Pisa 56127, Italy

e-mail: marco.grazzi@sssup.it

C. Tomasi

Department of Economics, University of Trento, Trento, Italy

A. Zeli

ISTAT, Roma, Italy boosting such intra-industry differences. Given such wide heterogeneities we resort to quantile regressions to identify the impact of a set of regressors at different levels of the conditional distribution of labor productivity. One phenomenon that we observe is what we call a tendency toward "neo-dualism" involving the co-existence of a small group of dynamic firms with a bigger ensemble of much less technologically progressive ones.

Keywords Productivity · Firm dynamics · Market selection · Trade - Euro introduction . Quantile regressions

JEL Classifications $\mathrm{C} 14 \cdot \mathrm{D} 20 \cdot \mathrm{F} 10 \cdot \mathrm{L} 10 \cdot$ L16 - L25

\section{Introduction}

In this paper, exploiting a newly developed database of Italian microdata, we investigate the firm-level dynamics underlying the flat trend in the aggregate productivity of Italian manufacturing industry.

A first striking feature that emerges from the empirical analysis is the high degree of heterogeneity of firms in the same sector along many dimensions of performance including labor productivity and growth rates (the results corroborate and refine those of Bottazzi et al. 2007). This heterogeneity is an 
intrinsic property of industries, no matter the chosen level of disaggregation. In that, our evidence is in good agreement with an ample literature showing it to be a very robust stylized fact, irrespective of the period, the sector, or the country (see, among others, Dunne et al. 1988, 1989; Haltiwanger et al. 1999; Bartelsman and Doms 2000).

The parameterization of the distributions also reveals that, given a general fat-tail property, the left tail is much fatter than the right tail. This, in turn, corresponds to greater heterogeneity in the performance of low-productivity firms, as opposed to the relative steepness of the right tail which is pointing to a few firms placed near some "efficiency frontier". The trend over time of such shapes confirms the persistently large differences in performances. Further, we also show that there is evidence of a widening of the differences between the most and least productive firms in each sector.

Second, as far as productivity is concerned our analyses highlight the apparent weakness of markets in selecting more efficient firms. The support of the sectoral distribution of firms' productivity is very wide and does not shrink over time, notwithstanding the "Euro" shock that occurred during the period investigated. The event, which can be regarded as equivalent to a trade liberalization shock with perfectly fixed exchange rates, could have been expected to foster a selection process causing the exit of the least efficient firms and, as a result, contribute to shrinking of the support of the distribution of productivity among surviving firms. One cannot rule out that such evidence stands for a long transient: in line with the transition dynamics literature (Lilien 1982; Davis et al. 1996), the increased dispersion following the Euro introduction could be the outcome of the fact that only some firms undertake restructuring activity while others do not, so that performance diverges at least in the short run. This interpretation is suggested by Bugamelli et al. (2010), who observed a high dispersion of firms' performance in the Euro period, and interpret it in terms of uneven paces of restructuring across different firms.

A priori, good candidates for an explanation of the striking differences across firms, even within the same line of business, ought to include firm-specific features which are sufficiently inertial over time and only in a limited way "plastic" to strategic manipulation so that they can be considered, at least in the short term, "state variables" rather than "control variables" for the firm (Winter 1987; Dosi et al. 2008). In fact, an emerging capability-based theory of the firm (Teece et al. 1994), identifies a fundamental source of differentiation across firms in their distinct problem-solving knowledge yielding different abilities of "doing things" - searching, developing new products, manufacturing, etc. Successful corporations, as argued in more detail in the introduction to Dosi et al. (2000), derive competitive strength from their above-average performance in a small number of capability clusters. Symmetrically, laggard firms often find it hard to imitate the perceived best-practice production techniques because of the difficulty of identifying the combination of routines and organizational traits which makes companies good at doing whatever they do.

Among the possible "state" variables idiosyncratically associated with any one firm, we focus here upon innovation (as indicated by the patenting activity of the firm) as it entails specific organizational forms and capabilities not easy to acquire by the firm in the short-term, and being or not being an exporter. Empirical evidence has provided rather robust support of the existence of a positive correlation between some proxies of innovation and firm productivity (see, among others, Dunne 1994; Hall and Mairesse 1995; Bartelsman and Dhrymes 1998). Moreover, a large number of micro-level studies have indicated that differences in firm performances within sectors are strongly correlated with the firm decision to engage in international transactions (Roberts and Tybout 1997; Bernard and Jensen 1995, 1999). Aw et al. (2008) show also that there is an interaction effect between firm's exporting activities and R\&D investment in explaining productivity change. In this respect we found that, third, exporting and patenting activity are associated with different "types" of firms as revealed also in terms of the productivity distributions. Hence, as far as productivity is concerned, firms exporting and/or patenting enjoy a superior performance than their non-exporting/non-patenting competitors: there is very robust evidence which is valid in almost all sectors and years of analysis (see also Castellani and Zanfei 2007; Serti and Tomasi 2008). On the other hand, if we look at the profitability of the firm (as indicated by the ratio of returns to sales) the picture is more blurred. Labor 
productivity and innovation (patenting) are strongly related to the capability of the firm to generate profits, while this is not the case for exporting activity as such (see also Grazzi 2009).

Fourth, our data do reveal a (very) small number of "outliers"-top performers in terms of labor productivity, innovation, export, and growth. However, their small number and share of value added compared with all the firms considered, is unable-at least up to 2004, our last year of observation-to affect the dynamics of the overall mean or even the shape of the relevant distributions over time.

\section{Data and descriptive statistics}

The database used for the analyses, Micro.3, has been built as a result of collaboration between the Italian statistical office, ISTAT, and a group of LEM researchers from the Scuola Superiore Sant'Anna, Pisa. ${ }^{1}$

Micro. 3 is largely based on the census of Italian firms conducted yearly by ISTAT and contains information on firms with more than 20 employees in all sectors of the economy for the period 1989-2004. Further, it has been possible to link Micro.3 with other information collected by Istat, most notably for this work, data on international trade (COE) and patent data. Starting in 1998 the census of the whole population of firms only concerns companies with more than 100 employees, while in the range of employment 20-99, ISTAT directly monitors only a "rotating sample" which varies every five years. In order to complete the coverage of firms in that range Micro. 3 resorts, from 1998 onward, to data from the financial statement that limited liability firms have to disclose, in accordance to Italian law. ${ }^{2}$

In order to undertake intertemporal comparison, we deflate our data on current value variables making use of the 2 or 3 -digit sectoral production price index

\footnotetext{
$\overline{1}$ The database has been made available for work after careful censorship of individual information. More detailed information concerning the development of the database Micro.3 is given by Grazzi et al. (2009).

${ }^{2}$ Limited liability companies (società di capitali) have to provide a copy of their financial statement to the Register of Firms at the local Chamber of Commerce.
}

provided by ISTAT and taking 2000 as the reference year. ${ }^{3}$ The deflators are available from 1991 onward.

The performance of Italy in terms of productivity growth over the last fifteen years or so has been poor. International comparisons (OECD 2008) show that Italy ranked last in terms of growth of GDP per hour worked over the period 1995-2006 (OECD 2008, p. 17).

In general, the Italian economy registered zero growth in the years 2001-2005 and average annual growth below $1 \%$ in the previous period, 1995-2000. Only Spain did worse in this subperiod. The evidence for the manufacturing sector is even more dramatic: indeed if we consider the 1995-2005 period, the average growth rate of value added per employee is negative (OECD 2008). Again Italy is the only country, together with Spain, that registered a negative growth rate of productivity in the period under investigation.

One of the objectives of this paper is to use microdata to make sense of the flat trend in productivity observed at the aggregate level. A preliminary requirement in order to do that is that our dataset is indeed able to replicate the properties that we observe for the sectoral aggregate.

Table 1 reports sectoral ${ }^{4}$ measures of labor productivity from Micro.3, covering firms with over 20 employees, those for firms above 100 employees, in brackets, and Eurostat sectoral measures, covering the whole sector, in square brackets. The differences between the three reveal the robust positive relationship between size and labor productivity (for a related work on a previous version of the database, see Bottazzi and Grazzi 2010).

Averages are in general higher in 2004 than in 1995. However, as we shall see, the differences in the levels of average productivity are not always significant (more on this in the following text). Also notice that the comparisons of the levels of labor productivity over time suggest that the largest share of productivity growth occurred in the period 1995-2000.

\footnotetext{
${ }^{3}$ Istat provides the time series for the Italian economy at: http://con.istat.it/default.asp.

${ }^{4}$ Because of small number of observations, results for the coke and petroleum sector (NACE 23) are not reported.
} 
Table 1 Value added per employee (at constant 2000 prices) for firms above 20 employees, for firms above 100 employees (in brackets) and for the whole sector (Eurostat data; in square brackets)

\begin{tabular}{|c|c|c|c|c|}
\hline NACE & Sector & 1995 & 2000 & 2004 \\
\hline 15 & Food, beverages & $54.9(56.8)[49.2]$ & $58.3(61.3)[53.1]$ & $58.9(61.9)[\ldots]$ \\
\hline 17 & Textiles & $43.0(44.5)[37.6]$ & $43.2(45.2)[42.8]$ & $41.4(42.8)[41.3]$ \\
\hline 18 & Wearing, apparel & $32.3(41.8)[27.3]$ & $34.6(44.0)[34.1]$ & $36.4(46.4)$ [32.8] \\
\hline 19 & Leather, allied product & $37.4(46.1)[31.1]$ & $37.1(43.1)[35.8]$ & $38.3(45.5)[35.2]$ \\
\hline 20 & Wood manufacturing & $40.6(53.3)[34.1]$ & 40.9 (51.6) [42.7] & $41.9(53.3)$ [42.9] \\
\hline 21 & Paper, allied product & $63.9(69.9)$ [53.9] & $64.8(74.5)[58.7]$ & $67.1(75.7)[61.6]$ \\
\hline 22 & Printing, publishing & $59.9(67.1)[47.2]$ & 70.4 (87.7) [60.3] & $75.0(95.2)$ [64.5] \\
\hline 24 & Chemical products & $84.1(86.6)[75.2]$ & $82.0(85.0)[81.2]$ & $82.1(85.1)[74.2]$ \\
\hline 25 & Rubber, plastics & $52.2(56.0)[44.6]$ & $49.8(53.9)[49.3]$ & $49.0(52.1)$ [48.6] \\
\hline 26 & Non Met. Min. products & $57.4(64.2)[46.4]$ & $58.3(66.4)[54.4]$ & $60.2(68.0)[54.3]$ \\
\hline 27 & Basic metals & $67.2(70.0)[59.8]$ & $58.7(60.6)[59.5]$ & $60.2(63.1)[58.1]$ \\
\hline 28 & Metal product & $46.3(50.9)[39.8]$ & $45.6(51.5)[46.5]$ & $45.8(51.7)$ [44.9] \\
\hline 29 & Industrial machinery & $53.5(55.4)[48.5]$ & $53.0(55.2)[53.0]$ & $52.3(54.5)[53.8]$ \\
\hline 30 & Office machinery & $74.4(77.3)[52.4]$ & $49.3(45.0)[50.2]$ & $66.3(83.2)$ [50.7] \\
\hline 31 & Electrical machinery & $47.5(49.8)[41.8]$ & $48.3(50.7)[46.3]$ & $49.7(53.4)[48.2]$ \\
\hline 32 & Radio, TV, etc. & 43.8 (43.6) [42.3] & $60.9(65.3)$ [64.9] & $61.7(65.4)$ [56.5] \\
\hline 33 & Med., Prec.,Opt. Instr. & $49.8(50.8)$ [46.9] & $51.5(55.0)[56.2]$ & $55.2(59.1)[56.9]$ \\
\hline 34 & Motor vehicles & $46.6(46.8)[43.1]$ & 45.7 (45.9) [44.8] & $52.1(53.2)[41.2]$ \\
\hline 35 & Other transp. equip. & $52.2(53.9)[\ldots]$ & $54.2(56.5)[50.2]$ & $58.5(61.2)[56.2]$ \\
\hline 36 & Furniture manufacturing & $39.1(43.6)[33.0]$ & 40.3 (45.7) [41.9] & 37.7 (41.3) [37.7] \\
\hline
\end{tabular}

Source Our elaboration on Micro.3 and Eurostat

\section{Intra-sectoral heterogeneity and its dynamics}

Let us turn now to firm level productivity to investigate the properties and evolution of the distributions over time. Dosi and Grazzi (2006) have already shown, for a shorter window using the same database, that labor productivity displays a wide support, both at three and two-digit levels of disaggregation. Further, it was also shown that such heterogeneity is highly persistent over time. What happened to such distribution after the shock associated with the introduction of the Euro currency?

In order to better investigate the distribution of the variable of interest, we will resort to a new family of distributions, the asymmetric exponential power (AEP) distribution, introduced by Bottazzi and Secchi (forthcoming) that enable proper accounting for asymmetries and leptorkurtosis, with normality as a special case. ${ }^{5}$

\footnotetext{
5 The AEP density has the following functional form (Bottazzi and Secchi, forthcoming)
}

In the following discussion we are going to use the AEP because it enables more flexible characterization of the distributions of labor productivity. In particular, we will investigate the dynamics over time and across sectors of the left and right tail parameters, $b_{l}$ and $b_{r}$, respectively, thus also accounting for possible asymmetries in the distributions. ${ }^{6}$

Footnote 5 continued

$f_{\mathrm{AEP}}(x ; \mathbf{p})=\frac{1}{C} e^{-\left(\frac{1}{b_{l}}\left|\frac{x-m}{a_{l}}\right|^{b_{l}} \theta(m-x)+\frac{1}{b_{r}}\left|\frac{x-m}{a_{r}}\right|^{b_{r}} \theta(x-m)\right)}$

where $\mathbf{p}=\left(b_{l}, b_{r}, a_{l}, a_{r}, m\right), \theta(x)$ is the Heaviside theta function and where the normalization constant reads $C=a_{l} A_{0}\left(b_{l}\right)+a_{r}$ $A_{0}\left(b_{r}\right)$ with

$A_{k}(x)=x^{\frac{k+1}{x}-1} \Gamma\left(\frac{k+1}{x}\right)$.

The two positive shape parameters $b_{r}$ and $b_{l}$, describe the tail behavior in the upper and lower tails, respectively; two positive scale parameters $a_{r}$ and $a_{l}$, are associated with the distribution width above and below the modal value and one location parameter $m$, represents the mode. The AEP reduces to the exponential power distribution Subbotin (1923) when $a_{l}=a_{r}$ and $b_{l}=b_{r}$.

${ }^{6}$ The $a_{l}$ and $a_{r}$ are substantially stable and are not reported. 

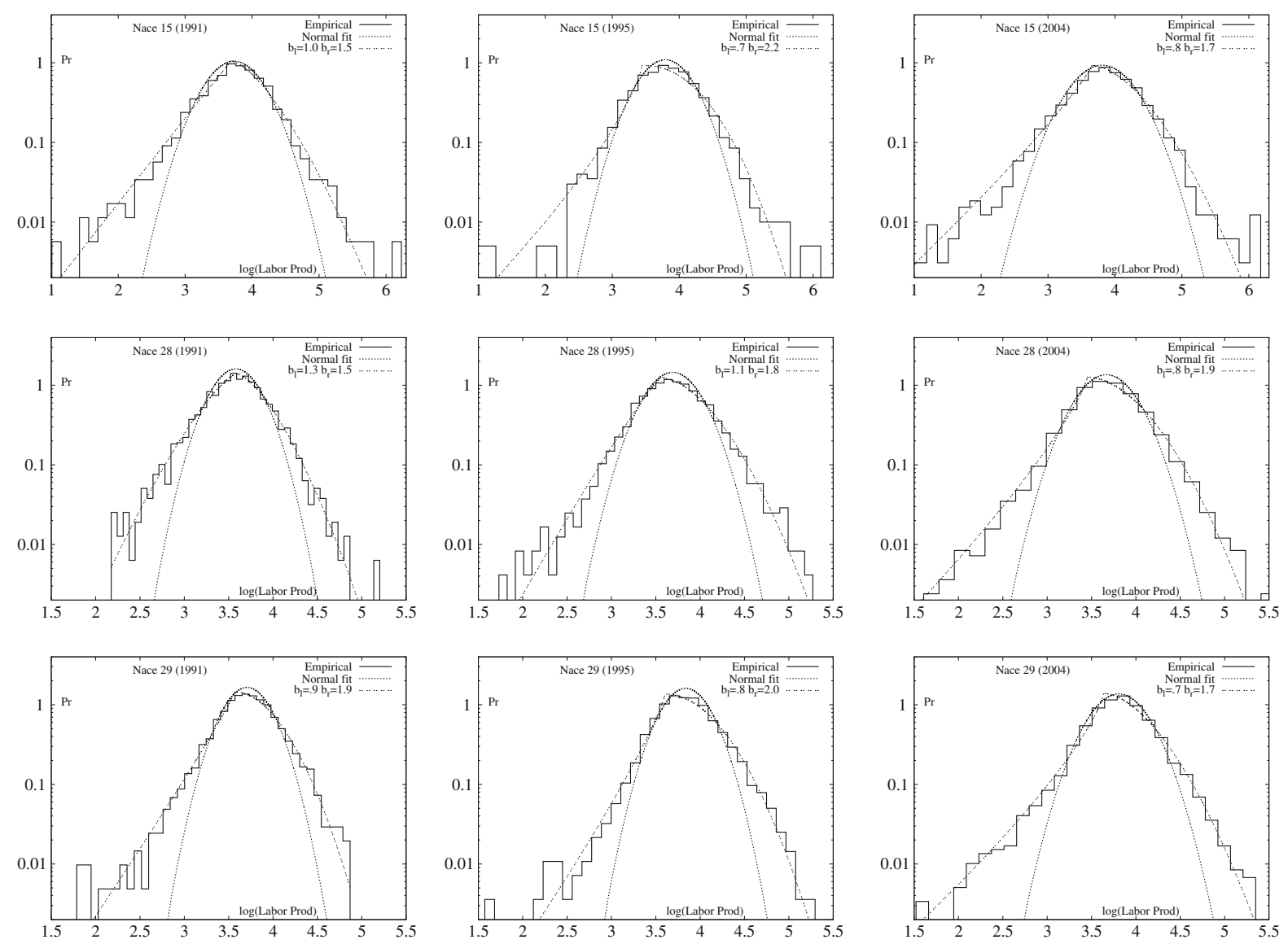

Fig. 1 Empirical density of labor productivity for the food and beverage sector (NACE 15), metal products (NACE 28), and industrial machinery (NACE 29) together with the normal and AEP fits. Probabilities on the y-axis are on a log scale

Figure 1 displays the empirical density of (log) labor productivity for the food and beverage sector (NACE 15), fabricated metal products (NACE 28), and the machine tool sector (NACE 29), together with the normal and AEP fits for a selection of years. In all sectors, the departure from normality of the empirical distribution is impressive both with regard to the wideness of the support and also for the asymmetry of the two tails, which is also visually detectable in the plots. It is also noteworthy that there is no shrink in the support of the distributions, suggesting persistently wide heterogeneity in the levels of efficiency. On the contrary, one detects a widening of the support. This piece of evidence does not seem to agree the conjecture that the introduction of the Euro has fostered any selection processes as a result of tighter competition.
The properties of the distributions that are revealed by the plots of Fig. 1 are valid for most of sectors, as shown by Table 2 . Notice, indeed, that almost all $b$ parameters in all sectors and years are $<2$, meaning that the distribution has fat-tail properties. Another equally remarkable feature is the asymmetry of the empirical density: the left index is often smaller than the right one, suggesting that the fat-tail property is stronger at the "low efficiency" side of the distribution. In fact, the $b_{l}$ coefficient is informative of different degrees of sectoral tolerance of inefficient firms. While the upper tail is likely to be constrained by the "frontier" state of technological knowledge, the evidence suggests a much looser constraint on the side of market selection, which should plausibly operate against less efficient firms. Moreover note that both the $b_{l}$ and $b_{r}$ coefficients have not changed 
Table 2 Summary table of the sectors under analysis

\begin{tabular}{|c|c|c|c|c|c|c|c|c|}
\hline \multirow[t]{2}{*}{ NACE } & \multicolumn{2}{|l|}{1991} & \multicolumn{2}{|l|}{1995} & \multicolumn{2}{|l|}{2000} & \multicolumn{2}{|l|}{2004} \\
\hline & $b_{l}$ & $b_{r}$ & $b_{l}$ & $b_{r}$ & $b_{l}$ & $b_{r}$ & $b_{l}$ & $b_{r}$ \\
\hline 15 & $1.01(0.08)$ & $1.48(0.14)$ & $0.76(0.06)$ & $2.23(0.17)$ & $0.91(0.06)$ & $1.75(0.12)$ & $0.87(0.05)$ & $1.73(0.12)$ \\
\hline 17 & $1.25(0.11)$ & $1.91(0.18)$ & $1.52(0.13)$ & $1.39(0.14)$ & $0.99(0.06)$ & $1.69(0.12)$ & $1.06(0.07)$ & $1.32(0.11)$ \\
\hline 18 & $1.04(0.09)$ & $1.30(0.10)$ & $1.08(0.10)$ & $1.29(0.09)$ & $1.09(0.09)$ & $1.46(0.12)$ & $1.09(0.10)$ & $1.63(0.14)$ \\
\hline 19 & $0.92(0.09)$ & $1.95(0.18)$ & $0.88(0.09)$ & $1.85(0.15)$ & $0.68(0.05)$ & $2.32(0.16)$ & $0.61(0.04)$ & $2.21(0.16)$ \\
\hline 20 & $1.01(0.13)$ & $1.58(0.21)$ & $0.76(0.08)$ & $1.59(0.18)$ & $0.65(0.05)$ & $1.73(0.16)$ & $0.87(0.08)$ & $1.70(0.18)$ \\
\hline 21 & $0.57(0.07)$ & $3.14(0.42)$ & $1.19(0.23)$ & $1.90(0.29)$ & $0.78(0.08)$ & $1.68(0.18)$ & $0.50(0.04)$ & $2.32(0.22)$ \\
\hline 22 & $0.81(0.10)$ & $1.70(0.16)$ & $0.85(0.09)$ & $1.25(0.12)$ & $0.82(0.07)$ & $1.21(0.09)$ & $0.69(0.06)$ & $1.45(0.11)$ \\
\hline 24 & $0.62(0.06)$ & $2.43(0.24)$ & $0.86(0.10)$ & $1.78(0.18)$ & $1.12(0.10)$ & $1.38(0.14)$ & $0.78(0.06)$ & $1.56(0.12)$ \\
\hline 25 & $0.79(0.07)$ & $1.87(0.17)$ & $0.68(0.05)$ & $1.98(0.16)$ & $0.93(0.06)$ & $1.67(0.11)$ & $0.79(0.04)$ & $1.63(0.11)$ \\
\hline 26 & $1.07(0.10)$ & $1.70(0.15)$ & $0.85(0.07)$ & $2.48(0.21)$ & $0.81(0.05)$ & $1.67(0.11)$ & $0.86(0.06)$ & $1.67(0.11)$ \\
\hline 27 & $0.81(0.09)$ & $2.27(0.26)$ & $0.99(0.14)$ & $1.88(0.23)$ & $0.99(0.10)$ & $1.55(0.16)$ & $0.70(0.06)$ & $1.69(0.15)$ \\
\hline 28 & $1.34(0.10)$ & $1.52(0.12)$ & $1.10(0.08)$ & $1.78(0.11)$ & $0.93(0.04)$ & $1.64(0.07)$ & $0.81(0.03)$ & $1.87(0.07)$ \\
\hline 29 & $0.93(0.06)$ & $1.94(0.12)$ & $0.85(0.05)$ & $2.01(0.11)$ & $0.83(0.03)$ & $1.53(0.06)$ & $0.77(0.03)$ & $1.73(0.07)$ \\
\hline 31 & $0.66(0.05)$ & $2.07(0.20)$ & $1.12(0.12)$ & $1.33(0.15)$ & $0.99(0.08)$ & $1.29(0.11)$ & $0.80(0.06)$ & $1.57(0.12)$ \\
\hline 32 & $0.90(0.14)$ & $1.17(0.24)$ & $1.92(0.34)$ & $0.80(0.13)$ & $0.71(0.08)$ & $2.04(0.26)$ & $0.72(0.10)$ & $2.42(0.34)$ \\
\hline 33 & $1.40(0.26)$ & $1.46(0.30)$ & $1.77(0.24)$ & $0.85(0.12)$ & $0.76(0.07)$ & $2.11(0.23)$ & $0.83(0.09)$ & $1.89(0.20)$ \\
\hline 34 & $0.93(0.12)$ & $1.46(0.24)$ & $0.40(0.04)$ & $2.56(0.33)$ & $0.54(0.04)$ & $1.67(0.16)$ & $0.69(0.07)$ & $1.64(0.17)$ \\
\hline 36 & $0.87(0.06)$ & $1.40(0.10)$ & $0.74(0.05)$ & $1.97(0.13)$ & $0.51(0.02)$ & $1.94(0.10)$ & $0.73(0.04)$ & $1.58(0.09)$ \\
\hline
\end{tabular}

Estimated $b_{l}$ and $b_{r}$ coefficients and standard errors for the distribution of labor productivity (deflated with the sectoral production price index)

much over time. If any pattern is detectable, it is of a relative decrease ${ }^{7}$ in the $b_{l}$ coefficients over time, This is also suggested by the higher number of dots representing three-digit sectors ${ }^{8}$ lying below the 45-degree line in Fig. 2.

A more succinct account of the widening of the support is offered by the ratio of the top and bottom productivity deciles for firms in each two-digit sector (Fig. 3). The plot shows that in 1991 the $10 \%$ most productive firms in each sector were (at least) two and a half times more productive than firms in the lowest decile. Such dispersion in performances within the industry has been widening, as shown in Fig. 3, where almost all dots lie above the 45-degree line. Again the widening of the support signals that the market does

\footnotetext{
7 Smaller $b$ corresponds to fatter tails.

${ }^{8}$ Quite obviously, more disaggregated three-digit sectors have many fewer observations than the corresponding two-digit sectors in which they are nested. Thus in order to recover a higher number of observations we pool together observations at the beginning (1991-92) and at the end (2003-04) of the period of observation.
}

not appear to exert a strong discipline in selecting in favor of the most efficient firms and in causing the exit of the least efficient ones. Using the same dataset, Bottazzi et al. (2010) address in detail the issue of selection by considering, in a sort of evolutionary accounting exercise, the decomposition of the growth of labor productivity in any one industry between the reallocation of market shares to the more productive firms and the increase in productivity because of firmlevel effects (the so-called "within" component): most growth, when it occurs, is because of the latter. This is in agreement with empirical analyses by Bugamelli et al. (2010) which suggest that the introduction of the Euro has induced more within-firm changes (restructuring) rather than relative reallocation of shares of output and employment across firms.

Having identified the characteristics of the distributions of labor productivity, what can we say about its growth rates?

A robust property is that they have a tent-like shape, that is, they also are fat-tailed (Bottazzi et al. 2005); further they are symmetric with values of $b_{l}$ and $b_{r}$ close to unity. Here let us check the properties 

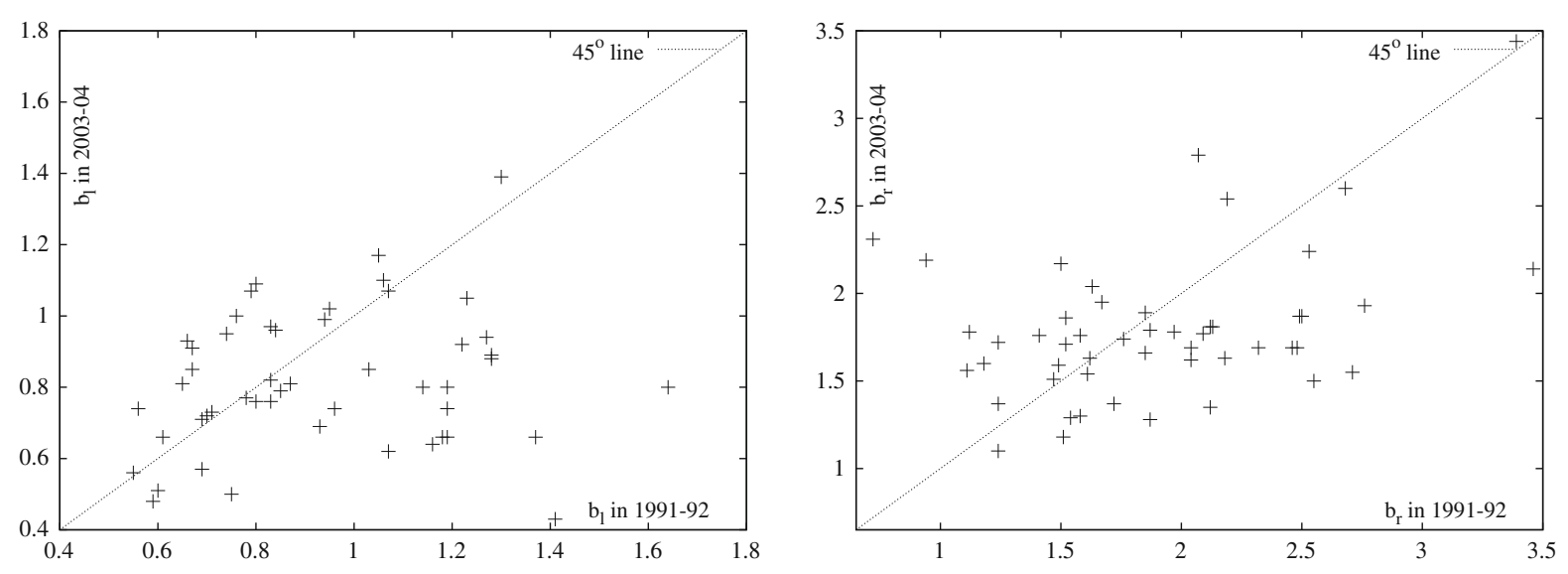

Fig. 2 Estimated $b_{l}$ (left) and $b_{r}$ (right) coefficients in 1991-92 and 2003-04 for three-digit sectors

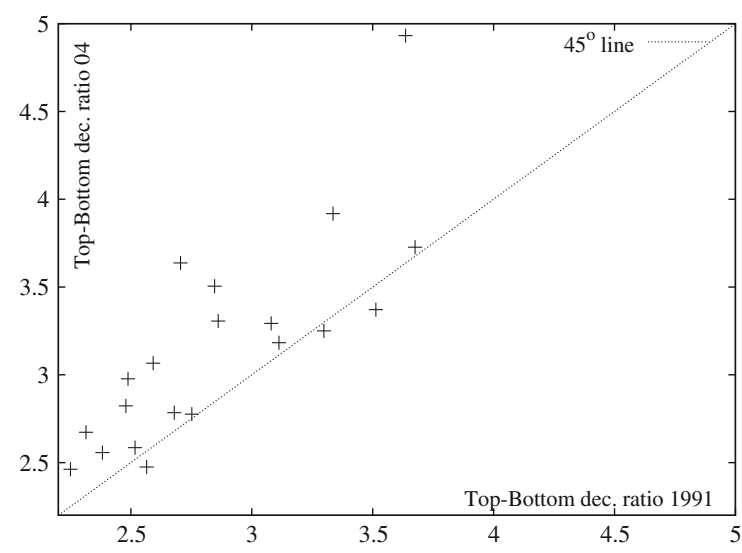

Fig. 3 Ratio of the average productivity of the top decile over the bottom for manufacturing sectors (1991 and 2004)

of growth rates of productivity also for intervals longer than one year, trying to see whether the process of temporal aggregation has any relevant effect on the distribution of growth rates. In this respect, Fig. 4 reports for sectors 15, 28, and 29, the growth rates of labor productivity for two five-year intervals, 1991-95 and 2000-04, over which the growth rate is defined as the logarithmic difference of the average labor productivity in the last three years and the average productivity in the first two years of the subsample. The reason for such a measure lies in the attempt to capture "longer-term" (and relatively stable) increases in labor productivity. The plots in Fig. 4 reveal that growth rates computed for such intervals also have a tent-like Laplacian shape. Such a long term "lumpiness" of productivity growth events clearly militates against the notion of productivity growth as a result of a smooth process made by small improvements. Rather, it appears often characterized by "big" idiosyncratic shocks.

\subsection{Fligner and Policello test}

We have seen that the distribution of labor productivity across firms is persistently wide, with supports that seem to have widened with time. However, given their fat-tailed asymmetric shapes, one can hardly study their possible change over time by simply comparing averages.

Thus, in order to gain statistical precision in comparison of the distributions of productivity in two different periods, we will perform formal tests of distributional equality based on the notion of stochastic (in)equality proposed by Fligner and Policello (1981). Let $F_{t}$ and $F_{p}$ be the distributions of the variable of interest for the two periods $t$ and $p$, respectively. Let us denote by $X_{t} \sim F_{t}$ and $X_{p} \sim F_{p}$ the associated random variables, and by $X_{t}$ and $X_{p}$ the two respective realizations. The distribution $F_{t}$ is said to dominate $F_{p}$ if $\operatorname{Prob}\left\{X_{t}>X_{P}\right\}>1 / 2$. That is, if one randomly selects two firms, one from the $t$ period and one from the $p$ period, the probability that the latter has a smaller value of $X$ is more than $1 / 2$, or, in other terms, it has a higher probability of having the smaller value. Since:

$\operatorname{Prob}\left\{X_{t}>X_{p}\right\}=\int d F_{t}(X) F_{p}(X)$,

a statistical procedure to assess which of the two distributions dominates can be formulated as a test of: 

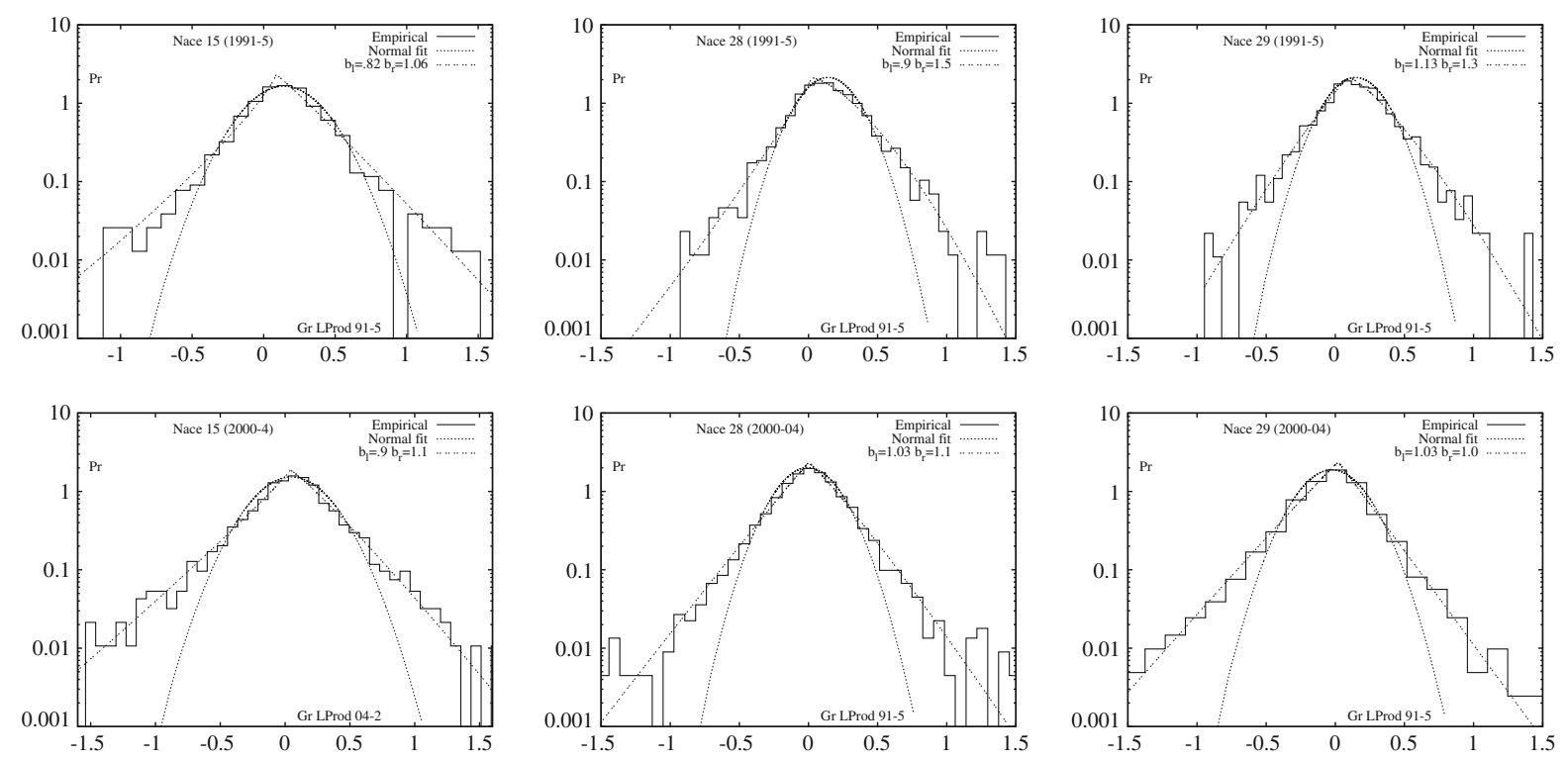

Fig. 4 Empirical density of growth rates of labor productivity over five-year periods, for the sector of food and beverages (NACE 15), metal products (NACE 28), and industrial

$H_{0}: \int d F_{t} F_{p}=\frac{1}{2} \quad$ vs $\quad H_{1}: \int d F_{t} F_{p} \neq \frac{1}{2}$.

The procedure developed by Fligner and Policello (1981) provides a valid statistic for $H_{0}$. We apply their procedure exploiting the fact that, in case of rejection of the null, the sign of the FlignerPolicello (FP) statistic tells us which of the two distributions is dominating: a positive (negative) sign means that productivity in period $t$ has a greater probability of taking on higher values than in the other period. The test does not assumes either normality or equal variances and it can be interpreted as a test of stochastic (in)equality between the two distributions. We will use the FlignerPolicello statistics to compare the levels of productivity in different years. The analysis is performed taking 2004 as our benchmark year, with which the distributions from the other years are compared. A positive (negative) value of the statistics means that productivity was higher (lower) in 2004 than in the year of comparison. Values of the test statistics that are significant at the 5\% level are in bold. Given the non-parametric nature of the test we require a minimum of 50 observations; hence we are bound to undertake it at the level of two-digit sectors and only in some three-digit ones. machinery (NACE 29), together with the normal and AEP fits. Productivity is deflated with the sectoral production price index. Probabilities on the $y$-axis are on a log scale

The evidence from Table 3 for 20 two-digit sectors is not encouraging. In the post-Euro subsample, 1999-2004, for most sectors it is not possible to conclude that productivity was higher in 2004 than in other years. One has to go back to the first subperiod 1991-95, and compare the distributions of labor productivity with that of 2004 , to find that in most sectors the distribution has shifted to the right.

In Table 4 we focus again on comparison of productivity in different years, and we consider averages over two consecutive years. Column (I) of Table 4 reports the results of the FP test on the distribution of labor productivity in 1991-92 versus 1994-95. The results of the test support the hypothesis that the larger part of the (yet small) increase in productivity mostly occurred in the first subperiod. Indeed, the comparisons of labor productivity in 1991-92 versus 1994-95 suggest that in most sectors there has been a shift in the distributions, whereas this is not true when comparing 1999-2000 and 2003-04 (column IV). In order to recover significant differences between the distribution of labor productivity one has to compare the first two years, 1991-92, with the very last two, 2003-04 (column II). It is only when we are considering the complete stretch of the sample period that we get clear evidence of an 


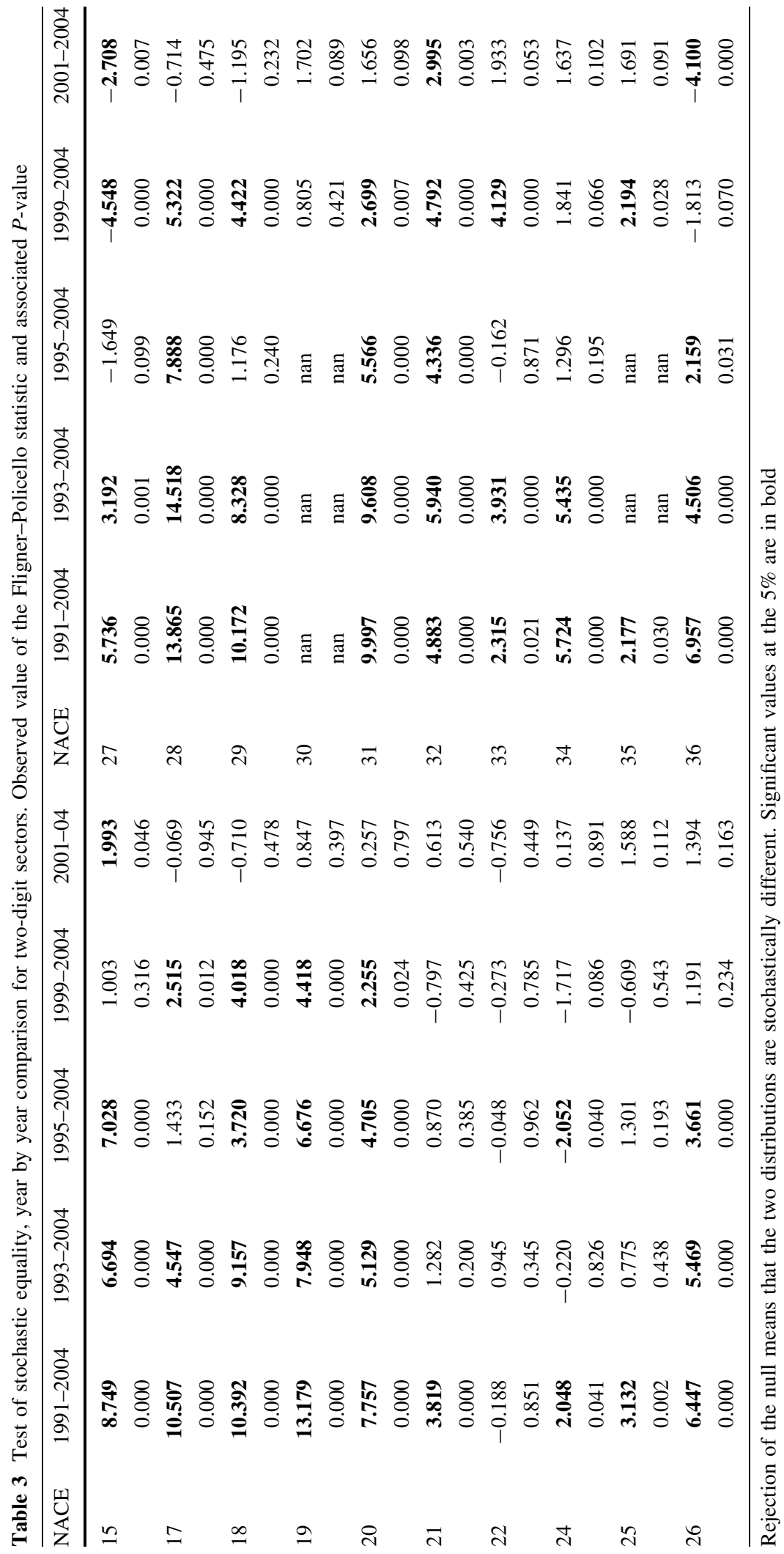


Table 4 Test of stochastic equality. Observed value of the Fligner-Policello statistic and associated $p$-value

\begin{tabular}{|c|c|c|c|c|c|c|c|c|c|}
\hline NACE & $\begin{array}{l}1991-92 \\
\text { vs. 1994-95 } \\
\text { (I) }\end{array}$ & $\begin{array}{l}\text { 1991-92 } \\
\text { vs. 2003-04 } \\
\text { (II) }\end{array}$ & $\begin{array}{l}1994-95 \\
\text { vs. 2003-04 } \\
\text { (III) }\end{array}$ & $\begin{array}{l}\text { 1999-2000 } \\
\text { vs. 2003-04 } \\
\text { (IV) }\end{array}$ & NACE & $\begin{array}{l}1991-92 \\
\text { vs. 1994-95 } \\
\text { (I) }\end{array}$ & $\begin{array}{l}\text { 1991-92 } \\
\text { vs. 2003-04 } \\
\text { (II) }\end{array}$ & $\begin{array}{l}1994-95 \\
\text { vs. 2003-04 } \\
\text { (III) }\end{array}$ & $\begin{array}{l}1999-2000 \\
\text { vs. 2003-04 } \\
\text { (IV) }\end{array}$ \\
\hline \multirow[t]{2}{*}{15} & 2.426 & 5.986 & 5.614 & 2.308 & 27 & 9.172 & 9.188 & 1.893 & -3.179 \\
\hline & 0.015 & 0.000 & 0.000 & 0.021 & & 0.000 & 0.000 & 0.058 & 0.001 \\
\hline \multirow[t]{2}{*}{17} & 11.172 & 12.384 & 0.692 & -0.260 & 28 & 10.956 & 11.847 & 6.782 & 5.768 \\
\hline & 0.000 & 0.000 & 0.489 & 0.795 & & 0.000 & 0.000 & 0.000 & 0.000 \\
\hline \multirow[t]{2}{*}{18} & 8.694 & 14.351 & 7.012 & 3.148 & 29 & 14.279 & 8.509 & -0.952 & -0.271 \\
\hline & 0.000 & 0.000 & 0.000 & 0.002 & & 0.000 & 0.000 & 0.341 & 0.787 \\
\hline \multirow[t]{2}{*}{19} & 8.561 & 12.696 & 6.235 & 1.390 & 30 & -1.223 & 0.793 & 1.477 & 1.302 \\
\hline & 0.000 & 0.000 & 0.000 & 0.165 & & 0.221 & 0.428 & 0.140 & 0.193 \\
\hline \multirow[t]{2}{*}{20} & 2.308 & 5.691 & 3.562 & 1.327 & 31 & 5.892 & 8.745 & 5.378 & 2.201 \\
\hline & 0.021 & 0.000 & 0.000 & 0.184 & & 0.000 & 0.000 & 0.000 & 0.028 \\
\hline \multirow[t]{2}{*}{21} & 6.169 & 4.579 & 0.062 & 1.707 & 32 & 2.663 & 2.158 & 1.926 & 4.034 \\
\hline & 0.000 & 0.000 & 0.950 & 0.088 & & 0.008 & 0.031 & 0.054 & 0.000 \\
\hline \multirow[t]{2}{*}{22} & 0.068 & -1.791 & 1.533 & -0.376 & 33 & 4.063 & 3.056 & -0.184 & 3.218 \\
\hline & 0.946 & 0.073 & 0.125 & 0.707 & & 0.000 & 0.002 & 0.854 & 0.001 \\
\hline \multirow[t]{2}{*}{23} & 0.117 & 1.656 & 1.310 & 0.176 & 34 & 5.920 & 4.651 & 0.107 & 1.425 \\
\hline & 0.907 & 0.098 & 0.190 & 0.860 & & 0.000 & 0.000 & 0.915 & 0.154 \\
\hline \multirow[t]{2}{*}{24} & 5.334 & 3.994 & 0.466 & -1.125 & 35 & 2.453 & 2.909 & 0.704 & 0.968 \\
\hline & 0.000 & 0.000 & 0.641 & 0.261 & & 0.014 & 0.004 & 0.482 & 0.333 \\
\hline \multirow[t]{2}{*}{25} & 4.021 & 0.423 & 1.932 & -0.242 & 36 & 5.732 & 4.746 & 0.531 & -3.477 \\
\hline & 0.000 & 0.672 & 0.053 & 0.809 & & 0.000 & 0.000 & 0.596 & 0.001 \\
\hline \multirow[t]{2}{*}{26} & 1.345 & 4.284 & 3.463 & 1.490 & & & & & \\
\hline & 0.179 & 0.000 & 0.001 & 0.136 & & & & & \\
\hline
\end{tabular}

Rejection of the null means that the two distributions are stochastically different. Significant values at the 5\% are in bold

increase in productivity. Indeed, the positive and significant signs in the other columns of Table 4 are very few. ${ }^{9}$ The evidence at the three-digit level, shown in Appendix A, is very much in agreement with that presented above.

Let us now turn to the intra-distributional dynamics of different firms.

\section{Firms' pecking orders and their dynamics}

As already shown by Dosi and Grazzi (2006), firm productivity is relatively stable over time with autoregressive coefficients close to unity. Further evidence on the persistence of the relative performance of firms can be captured by the transition

\footnotetext{
9 These results are largely invariant to the size of the firm. The same analysis applied to firms with more than 100 employees gives the same patterns.
}

probabilities across performance (in our case, productivity) quantiles. Indeed, other work has shown that year-to-year transition probabilities have very high persistence (Bartelsman and Dhrymes 1998), and this is also true for longer time intervals (Baily et al. 1992; see also Bartelsman and Doms 2000 for a review of the literature).

Table 5 reports the transition probability matrices over the period 2000-04 for a selection of sectors. Productivity in $t$ is defined as the average of productivity in 2000 and 2001 , and in $t+1$ as the average over the years 2002 to $2004 .{ }^{10}$ Quartile 1 is the one of firms with lowest productivity, quartile 4 that of firms with highest productivity. The evidence of Table 5 confirms the high persistency in the

\footnotetext{
$\overline{10}$ The period $2000-04$ is chosen to take advantage of the change in the data collection procedure (see Sect. 2), which made available financial statements for all limited liability companies.
} 
Table 5 Transition probability matrices between time $t$ (averages 2000-01) and $t+1$ (averages 2002-04) for the distribution of labor productivity

\begin{tabular}{|c|c|c|c|c|c|c|c|c|c|c|c|}
\hline NACE 15 & & $t+1$ & & & & NACE 26 & & $t+1$ & & & \\
\hline Food and beverage & & 1 & 2 & 3 & 4 & Non-met. min. product & & 1 & 2 & 3 & 4 \\
\hline \multirow[t]{4}{*}{$t$} & 1 & 71.54 & 24.30 & 2.70 & 1.35 & $t$ & 1 & 72.56 & 19.74 & 5.90 & 1.79 \\
\hline & 2 & 21.37 & 53.99 & 21.37 & 3.37 & & 2 & 23.08 & 51.79 & 21.79 & 3.33 \\
\hline & 3 & 5.17 & 19.35 & 58.04 & 17.55 & & 3 & 3.59 & 24.87 & 50.26 & 21.28 \\
\hline & 4 & 1.80 & 2.47 & 18.00 & 77.62 & & 4 & 0.77 & 3.59 & 22.05 & 73.59 \\
\hline NACE 17 & & $t+1$ & & & & NACE 27 & & $t+1$ & & & \\
\hline Textiles & & 1 & 2 & 3 & 4 & Basic metal & & 1 & 2 & 3 & 4 \\
\hline \multirow[t]{4}{*}{$t$} & 1 & 70.18 & 22.71 & 4.50 & 2.46 & $t$ & 1 & 68.03 & 25.57 & 5.31 & 0.97 \\
\hline & 2 & 21.89 & 47.47 & 24.76 & 5.73 & & 2 & 26.54 & 45.36 & 22.20 & 5.79 \\
\hline & 3 & 6.34 & 22.92 & 48.49 & 22.10 & & 3 & 4.34 & 26.54 & 53.56 & 15.44 \\
\hline & 4 & 1.43 & 6.75 & 22.10 & 70.18 & & 4 & 0.97 & 2.41 & 18.82 & 78.17 \\
\hline NACE 18 & & $t+1$ & & & & NACE 28 & & $t+1$ & & & \\
\hline Wearing and apparel & & 1 & 2 & 3 & 4 & Metal product & & 1 & 2 & 3 & 4 \\
\hline \multirow[t]{4}{*}{$t$} & 1 & 74.81 & 22.32 & 2.71 & 0 & $t$ & 1 & 70.29 & 23.00 & 5.29 & 1.37 \\
\hline & 2 & 20.21 & 61.24 & 14.78 & 3.92 & & 2 & 23.00 & 48.84 & 23.64 & 4.56 \\
\hline & 3 & 3.32 & 15.99 & 61.84 & 19.00 & & 3 & 5.48 & 24.28 & 51.12 & 19.17 \\
\hline & 4 & 1.51 & 0.60 & 20.81 & 76.92 & & 4 & 1.19 & 3.93 & 19.99 & 74.85 \\
\hline NACE 19 & & $t+1$ & & & & NACE 29 & & $t+1$ & & & \\
\hline Leather, allied product & & 1 & 2 & 3 & 4 & Industrial machinery & & 1 & 2 & 3 & 4 \\
\hline \multirow[t]{4}{*}{$t$} & 1 & 70.09 & 25.23 & 4.05 & 0.62 & $t$ & 1 & 64.06 & 26.51 & 7.19 & 2.17 \\
\hline & 2 & 22.43 & 54.21 & 21.50 & 1.87 & & 2 & 23.85 & 44.74 & 25.72 & 5.62 \\
\hline & 3 & 6.85 & 16.51 & 55.14 & 21.50 & & 3 & 8.08 & 22.37 & 45.13 & 24.34 \\
\hline & 4 & 0.62 & 4.05 & 19.31 & 76.01 & & 4 & 3.94 & 6.31 & 21.88 & 68.10 \\
\hline NACE 24 & & $t+1$ & & & & NACE 36 & & $t+1$ & & & \\
\hline Chemical product & & 1 & 2 & 3 & 4 & Furniture & & 1 & 2 & 3 & 4 \\
\hline \multirow[t]{4}{*}{$t$} & 1 & 70.35 & 21.33 & 7.11 & 1.12 & $t$ & 1 & 66.32 & 25.86 & 6.05 & 1.67 \\
\hline & 2 & 23.95 & 49.77 & 22.45 & 3.74 & & 2 & 22.73 & 49.22 & 24.40 & 3.75 \\
\hline & 3 & 4.86 & 22.45 & 51.26 & 21.33 & & 3 & 8.76 & 21.69 & 48.80 & 20.86 \\
\hline & 4 & 0.75 & 6.36 & 19.08 & 74.09 & & 4 & 2.09 & 3.34 & 20.86 & 73.62 \\
\hline
\end{tabular}

performance of firms, as denoted by the high probabilities on the main diagonal. Also note that the transition probabilities for the one-year interval, not reported here, are indicative of even higher persistency. Interestingly, the transition probabilities do not vary much among different sectors.

Further, note that probabilities are higher for the persistently low/high-performance firms: the probabilities of remaining in quartile 1 or quartile 4 are approximately equal to $70 \%$. Finally, in order to indirectly insulate the property of the dynamics of those firms that are and continue to be incumbents throughout the period, we have studied the properties of the transition probability matrices (TPMs) over the period 2000-04 of all firms that were already present in 1995 (not shown in the paper). Symmetrically we have studied the TPMs over the period 1998-2002 for firms that continued to be in the database until the end of the period of observation. However the dynamics of firms in the productivity distribution, as represented in terms of TPMs, did not change significantly. All the foregoing evidence hints at the existence of persistently different groups of firms co-existing in the same industry but characterized by distinct "identities" and performances.

Which characteristics of the groups of firms may one identify with the help of the transition probability matrix? In particular we will consider firms that lie 
Table 6 Definition of productivity laggards (A), climbers (B), leaders (C), and falling back (D)

\begin{tabular}{|c|c|c|c|c|c|}
\hline & & \multicolumn{4}{|c|}{$t+1$} \\
\hline & & 1 & 2 & 3 & 4 \\
\hline \multirow[t]{4}{*}{$\mathrm{t}$} & 1 & A & A & & B \\
\hline & 2 & A & A & & B \\
\hline & 3 & & & & \\
\hline & 4 & D & $\mathrm{D}$ & & $\mathrm{C}$ \\
\hline
\end{tabular}

persistently at the bottom of the productivity distribution, the "productivity laggards" (A); those that, in contrast, succeed in jumping to the top, i.e. the "productivity climbers" (B); those that have been persistently at the top of the productivity distribution, the "productivity leaders" (C); and, finally, "falling back" (D), those that fall behind in the productivity ranking. Refer to Table 6 for the definition of the four groups in the transition matrix.

Table 7 reports, for a selection of two-digit sectors, the characteristics of the four aforementioned groups of firms at the beginning of the reference periods, that is, 2000 and 2001. First, note the very low percentage of firms that climbed up or dropped down the productivity ranking. In terms of distinguishing features, the leaders tend to be bigger than laggards (size is measured by the log of employment). Further, climbers are, on average, much bigger then laggards, and occasionally, even bigger than leaders (see, for example, sector 15). That is, climbers are already bigger at the beginning of the reference period, before the productivity "take off" actually occurred. Second, both climbers and leaders are more active exporters than laggards. ${ }^{11}$ This is even more evident when one considers the number of countries a firm is trading with (Exp/Imp countr.), and also the number of products that the firm is exporting or importing (Exp/Imp NACE4). ${ }^{12}$ Third, climbers and leaders distinguish themselves from laggards also in terms of patenting activities. What is, however, rather puzzling is the difference in profitability, Prof $\%$, as indicated by gross operating margin

\footnotetext{
11 The export variable is the average of a yearly dummy on export activity.

12 The measure is in terms of the number of four-digit sectors in which the firms operate as an exporter and as an importer.
}

over total sales, ${ }^{13}$ in the four groups of firms. It turns out, indeed, that laggards are more profitable than climbers in all sectors considered. That is, laggard firms remain behind in the productivity distribution but their profit margins, although somewhat smaller than those of leaders, are larger than those of productivity climbers. Incidentally note that such evidence adds to the view that when considering the mechanisms of market selection (or lack of them) one ought to consider not only relative productivity but also relative profitabilities (cf. Foster et al. 2008).

To summarize: analysis of the intra-distributional dynamics and the associated firms' characteristics reveals an "ecology" of diverse co-existing types, also different in terms of export propensities and degrees of innovation, which tend to be rather persistent notwithstanding significantly different performances.

\section{The determinants of productivity growth}

Although, as we have seen, the growth in average sectoral productivity has been limited, it is important to identify the firm-level characteristics and behavior which are conducive (or hinder) productivity growth.

Let us begin with a simple model that relies on a cross-sectional regression: ${ }^{14}$

$\Delta y_{t, t+1}=\alpha+\beta_{1} \operatorname{Exp}_{i, t}+\beta_{2} P_{a t}+\beta_{3} Z_{i, t}+\varepsilon_{i}$

where $\Delta y_{t, t+1}$ is the growth of productivity measured as the logarithmic difference between the productivity in the periods $t$ and $t+1$. In order to account for possible effects of introduction of the Euro, we estimate equation (5) for the pre and post-Euro subperiods, 1991-95 and 2000-04, respectively. Accordingly, we will refer to the time index $t$ to denote the initial year and $t+1$ to denote the last year. To maximize the number of observations we take the average of a variable over the first two years

\footnotetext{
${ }^{13}$ Gross operative margin is valued added minus wages, salaries, and social insurances paid by the firm. We use this basic measure of profitability (GOM/total sales) as we expect it to be relatively less biased by accounting interferences than other indicators, for example net profits.

14 This specification has the advantage of reducing endogeneity problems between our main independent variables-export and innovation - and productivity growth, because both are predetermined. We also try to reduce possible bias due to unobserved heterogeneity by accounting for a number of firm's characteristics (see Bernard and Jensen 1999, for a similar regression).
} 


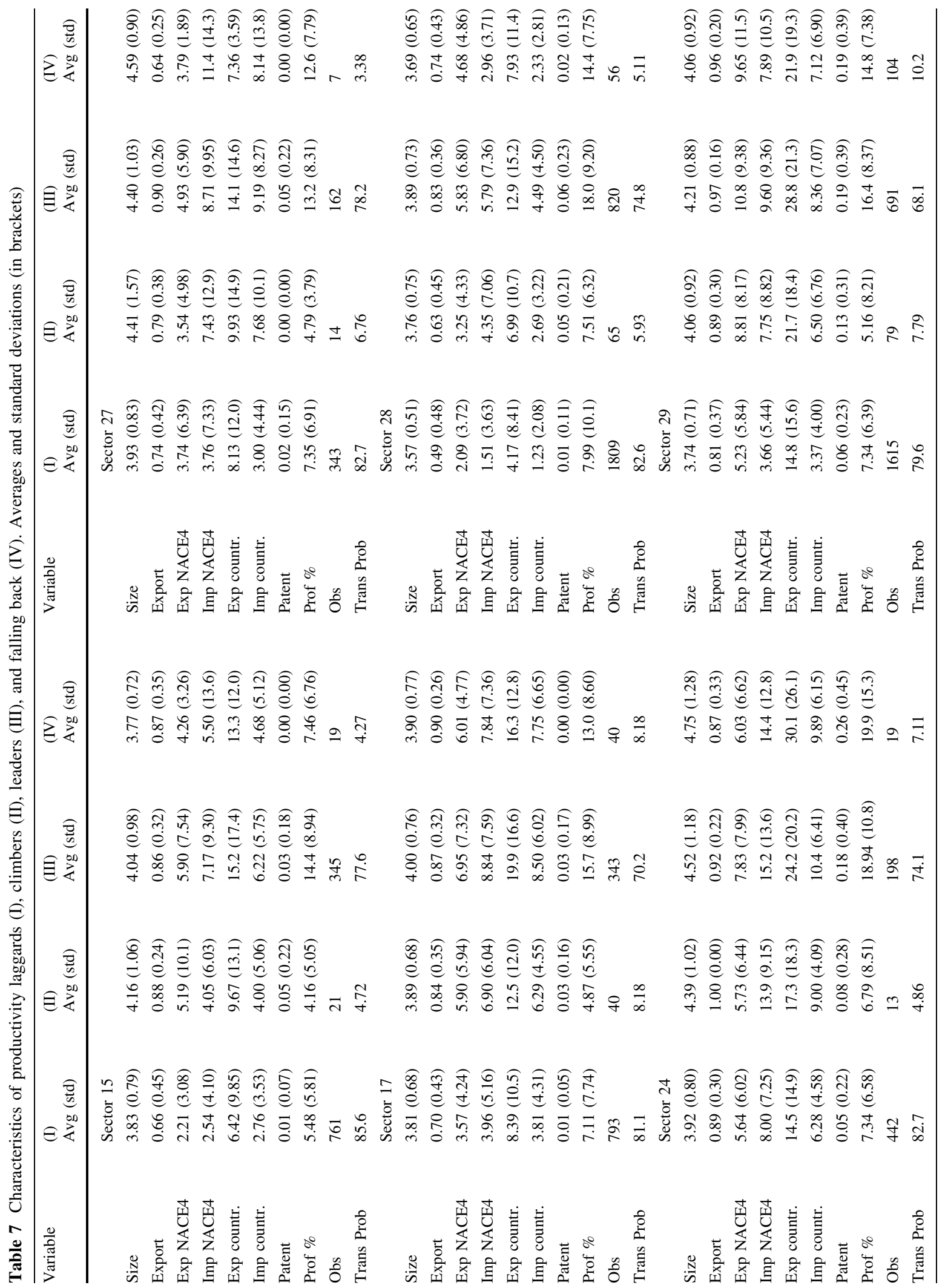


of each subperiod (1991-92 and 2000-01), and that over the last three years (1993-95 and 2002-04).

As independent variables we consider an export dummy $\left(\operatorname{Exp}_{i, t}\right)$ that takes value 1 if the firm was exporting at the beginning of the period over which the growth rate is computed ${ }^{15}$ and a patent dummy $\left(\right.$ Pat $\left._{i, t}\right)$ that takes a value of unity if the firm had any registered patents in the initial year $t .{ }^{16}$ As additional controls we include a vector $\left(Z_{i, t}\right)$ of firm-level characteristics evaluated at the initial year, which consists of a measure of (log) labor productivity, firm size (log of total employment), sectoral dummies at two-digit, and four regional dummies (north-west, north-east, center, south).

Results of regressions are reported in Table 8. In column (1) we report our baseline results with the exporter and the innovation dummy, whereas in column (2) we include other firm's attributes to control for the stability of the coefficients. To further control for different determinants and patterns of technological change, we re-run the specification of column (2), grouping firms according to the Pavitt taxonomy (Pavitt 1984): supplier dominated, specialized suppliers, scale dominated, and science-based firms. Results are reported in columns (3)-(6) of Table 8.

Let us focus on the top panel that reports results for the pre-Euro period. The estimates for both the export and the innovation variables remain positive and significant also with additional firm controls. Firms that have exported in the initial year have registered higher growth of productivity in the next period. This evidence is consistent with the idea puts forward by the recent literature of international trade according to which firms become more efficient when they export because of learning or economies of scale mechanisms (Clerides et al. 1998). While the empirical literature has found weak evidence in favor of the learning mechanisms observed here, rather robust support has been provided of self-selection effects of more productive firms into export. Using the same dataset and period, Serti and

\footnotetext{
15 For the pre-Euro subperiod the export dummy takes value one if the firm was exporting in both 1991 and 1992, or, for the post-Euro subperiod, in both 2000 and 2001. Note that the export status is very stable over time. If a firm is exporting in a given year there is a $90 \%$ chance it will be exporting in the following year also.

16 The patent dummy takes a value of unity if the firm had registered a patent in at least one of the two first years, 1991 and 1992 or 2000 and 2001. We consider patents registered at the USPTO or at the EPO.
}

Tomasi (2008) find evidence of both self-selection into export and learning effects using propensity score matching and difference-in-difference methods. ${ }^{17}$

The dummy accounting for registered patents is positive, suggesting that firms involved in innovation activities show significantly faster growth in productivity than those that do not patent, but this property crucially depends on the type of sector. The coefficient on the initial level of productivity is negative and significant, confirming the (relatively mild) regression-to-the-mean tendency already identified by Dosi and Grazzi (2006). As far as the initial size of the firm is concerned, that does seem to matter because it is statistically significant.

Looking at the regressions for the four Pavitt classes we observe that the sources of productivity growth may be distinct in different classes. The sign of the estimates of the export dummy do not change with respect to the whole sample, while the magnitude is higher for the supplier-dominated and science-based firms. The coefficient of the patent variable turns out to be statistically significant in all classes but the specialized suppliers. Results for the control variables are instead robust to the four classes. Even higher heterogeneity in the effect of the two main variables is detected when we run equation (5) sector by sector. ${ }^{18}$

Let us now turn to the post-Euro subperiod (bottom panel of Table 8). Some important regularities emerge from the data here also. As in the pre-Euro case, we observe that in all the different specifications, from column (2) to column (6), initial level of productivity is negatively correlated with productivity growth. When looking at the whole sample (column 2), both the patent dummy and the initial level of size have a positive and statistically significant effect on the productivity growth. However, the disaggregated analysis reveals that these variables are relevant only for some sectors. The dummy accounting for registered patents turns out to be statistically significant only in the supplier-dominated and scale-dominated classes. Also size matters only in

\footnotetext{
17 Note that, inevitably, our measure of productivity is not a physical one, but value added at constant prices. Granted that if exporters before the Euro found it possible to increase their Lira prices that could have showed up as a (spurious) augmentation in value added vis à vis non-exporters. Obviously that became impossible in the Euro era.

${ }^{18}$ In particular, only in few sectors is holding patents related to higher productivity growth in the following period. Results are reported in Appendix B.
} 
Table 8 Growth of productivity regression. OLS estimates. Standard errors in brackets

\begin{tabular}{|c|c|c|c|c|c|c|}
\hline & $\begin{array}{l}\text { (1) } \\
\text { Whole sample }\end{array}$ & $\begin{array}{l}\text { Whole sample } \\
\text { Who }\end{array}$ & $\begin{array}{l}\text { (3) } \\
\text { Supplier-dominated }\end{array}$ & $\begin{array}{l}\text { (4) } \\
\text { Specialized suppliers }\end{array}$ & $\begin{array}{l}\text { (5) } \\
\text { Scale-dominated }\end{array}$ & $\begin{array}{l}(6) \\
\text { Science-based }\end{array}$ \\
\hline & \multicolumn{6}{|c|}{ Productivity growth 1991-95 } \\
\hline \multirow[t]{2}{*}{$\operatorname{Exp}_{t}$} & 0.021 & 0.041 & 0.047 & 0.021 & 0.034 & 0.053 \\
\hline & $(0.005)$ & $(0.005)$ & $(0.012)$ & $(0.011)$ & $(0.012)$ & $(0.024)$ \\
\hline \multirow[t]{2}{*}{$\mathrm{Pat}_{t}$} & 0.057 & 0.071 & 0.061 & 0.054 & 0.112 & 0.077 \\
\hline & $(0.015)$ & $(0.014)$ & $(0.027)$ & $(0.038)$ & $(0.021)$ & $(0.042)$ \\
\hline \multirow[t]{2}{*}{$L P_{t}$} & & -0.218 & -0.174 & -0.209 & -0.252 & -0.168 \\
\hline & & $(0.012)$ & $(0.024)$ & $(0.030)$ & $(0.022)$ & $(0.035)$ \\
\hline \multirow[t]{2}{*}{ Size $_{t}$} & & 0.024 & 0.026 & 0.022 & 0.022 & 0.000 \\
\hline & & $(0.003)$ & $(0.008)$ & $(0.007)$ & $(0.006)$ & $(0.010)$ \\
\hline Sectoral dummies & Yes & Yes & - & - & - & - \\
\hline Regional dummies & Yes & Yes & Yes & Yes & Yes & Yes \\
\hline Observations & 14714 & 14714 & 8334 & 3229 & 2591 & 560 \\
\hline \multirow[t]{2}{*}{$R$-squared } & 0.02 & 0.10 & 0.09 & 0.11 & 0.11 & 0.12 \\
\hline & \multicolumn{6}{|c|}{ Productivity growth $2000-04$} \\
\hline \multirow[t]{2}{*}{$\operatorname{Exp}_{t}$} & -0.012 & 0.024 & -0.004 & 0.014 & 0.047 & 0.069 \\
\hline & $(0.005)$ & $(0.006)$ & $(0.006)$ & $(0.012)$ & $(0.019)$ & $(0.031)$ \\
\hline \multirow[t]{2}{*}{$\mathrm{Pat}_{t}$} & -0.010 & 0.022 & 0.039 & 0.002 & $\mathbf{0 . 0 3 0}$ & 0.044 \\
\hline & $(0.008)$ & $(0.008)$ & $(0.015)$ & $(0.017)$ & $(0.014)$ & $(0.029)$ \\
\hline \multirow[t]{2}{*}{$L P_{t}$} & & $-\mathbf{0 . 2 3 3}$ & -0.154 & -0.226 & -0.284 & -0.251 \\
\hline & & $(0.012)$ & $(0.016)$ & $(0.016)$ & $(0.037)$ & $(0.035)$ \\
\hline \multirow[t]{2}{*}{$\operatorname{Size}_{t}$} & & 0.014 & 0.010 & 0.003 & 0.016 & 0.004 \\
\hline & & $(0.003)$ & $(0.005)$ & $(0.006)$ & $(0.007)$ & $(0.013)$ \\
\hline Sectoral dummies & Yes & Yes & - & - & - & - \\
\hline Regional dummies & Yes & Yes & Yes & Yes & Yes & Yes \\
\hline Observations & 21505 & 21505 & 11492 & 4845 & 4171 & 997 \\
\hline$R$-squared & 0.01 & 0.11 & 0.06 & 0.11 & 0.12 & 0.14 \\
\hline
\end{tabular}

Coefficients significant at the $5 \%$ level are in bold. Our elaboration on Micro.3

these two groups. The most striking difference between pre and post-Euro introduction that emerges from Table 8 concerns the effect of export activity. In more recent years it seems that exporting is less associated with higher productivity growth.

More generally, firm characteristics seem a less important determinant of productivity in the postEuro period. This could be a signal of the fact that within each "type" of firm what is prevailing is the stagnation in productivity, so that the "type" does not affect significantly productivity dynamics.

A natural candidate to be among the determinants of productivity growth is investment activity, because it typically embodies productivity-enhancing process innovation. The variable however is not available for the entire sample. ${ }^{19}$

Table 9 reports the results for the subsample covering also the investment variable of a regression model equal to equation (5) where we add investments among the independent variables. As for the other variables, we consider the average of investments over

\footnotetext{
19 In particular, the variable "investment" is always available in the first subperiod, 1991-95, whereas in the second subperiod, 2000-04 it is only available for firms surveyed by Istat, the National Office of Statistics. That amounts to all firms above 100 employees and a representative sample of firms in the employment range 20-100.
} 
Table 9 Growth of productivity regression (II) with observed investments. OLS estimates. Standard errors in brackets

\begin{tabular}{|c|c|c|c|c|c|}
\hline & $\begin{array}{l}(1) \\
\text { Whole sample }\end{array}$ & $\begin{array}{l}\text { (2) } \\
\text { Supplier-dominated }\end{array}$ & $\begin{array}{l}\text { (3) } \\
\text { Specialized suppliers }\end{array}$ & $\begin{array}{l}\text { (4) } \\
\text { Scale-dominated }\end{array}$ & $\begin{array}{l}\text { (5) } \\
\text { Science-based }\end{array}$ \\
\hline & \multicolumn{5}{|c|}{ Productivity growth 1991-95 } \\
\hline \multirow[t]{2}{*}{$\operatorname{Exp}_{t}$} & 0.040 & 0.048 & $\mathbf{0 . 0 2 0}$ & $\mathbf{0 . 0 3 2}$ & 0.046 \\
\hline & $(0.005)$ & $(0.006)$ & $(0.010)$ & $(0.012)$ & $(0.024)$ \\
\hline \multirow[t]{2}{*}{$\mathrm{Pat}_{t}$} & 0.074 & 0.062 & 0.056 & 0.114 & 0.082 \\
\hline & $(0.014)$ & $(0.025)$ & $(0.037)$ & $(0.021)$ & $(0.042)$ \\
\hline \multirow[t]{2}{*}{$L P_{t}$} & -0.208 & $-\mathbf{0 . 1 7 9}$ & -0.189 & -0.249 & -0.165 \\
\hline & $(0.011)$ & $(0.009)$ & $(0.027)$ & $(0.021)$ & $(0.033)$ \\
\hline \multirow[t]{2}{*}{ Size $_{t}$} & $\mathbf{0 . 0 2 0}$ & 0.022 & 0.017 & 0.020 & -0.004 \\
\hline & $(0.003)$ & $(0.004)$ & $(0.007)$ & $(0.006)$ & $(0.010)$ \\
\hline \multirow[t]{2}{*}{$\operatorname{In} v_{t}$} & 0.269 & 0.307 & 0.254 & 0.223 & 0.538 \\
\hline & $(0.029)$ & $(0.042)$ & $(0.033)$ & $(0.092)$ & $(0.114)$ \\
\hline Sectoral dummies & Yes & - & - & - & - \\
\hline Regional dummies & Yes & Yes & Yes & Yes & Yes \\
\hline Observations & 14714 & 8334 & 3299 & 2591 & 560 \\
\hline \multirow[t]{2}{*}{$R$-squared } & 0.13 & 0.12 & 0.13 & 0.11 & 0.18 \\
\hline & \multicolumn{5}{|c|}{ Productivity growth $2000-04$} \\
\hline \multirow[t]{2}{*}{$\operatorname{Exp}_{t}$} & 0.022 & -0.009 & 0.007 & 0.068 & 0.079 \\
\hline & $(0.011)$ & $(0.014)$ & $(0.019)$ & $(0.040)$ & $(0.048)$ \\
\hline \multirow[t]{2}{*}{ Pat $_{t}$} & 0.011 & 0.022 & 0.002 & 0.020 & 0.038 \\
\hline & $(0.010)$ & $(0.020)$ & $(0.020)$ & $(0.017)$ & $(0.032)$ \\
\hline \multirow[t]{2}{*}{$L P_{t}$} & -0.217 & $-\mathbf{0 . 1 3 7}$ & -0.223 & -0.228 & -0.195 \\
\hline & $(0.014)$ & $(0.021)$ & $(0.022)$ & $(0.031)$ & $(0.041)$ \\
\hline \multirow[t]{2}{*}{ Size $_{t}$} & 0.011 & 0.015 & 0.001 & 0.003 & -0.008 \\
\hline & $(0.004)$ & $(0.007)$ & $(0.007)$ & $(0.010)$ & $(0.013)$ \\
\hline \multirow[t]{2}{*}{$\operatorname{In} v_{t}$} & 0.070 & 0.084 & 0.055 & 0.014 & 0.117 \\
\hline & $(0.026)$ & $(0.032)$ & $(0.074)$ & $(0.060)$ & $(0.040)$ \\
\hline Sectoral dummies & Yes & - & - & - & - \\
\hline Regional dummies & Yes & Yes & Yes & Yes & Yes \\
\hline Observations & 9574 & 3782 & 2610 & 1487 & 532 \\
\hline$R$-squared & 0.11 & 0.05 & 0.1 & 0.08 & 0.14 \\
\hline
\end{tabular}

Coefficients significant at the $5 \%$ level are in bold

value added in the first two years of every sub-period. First, notice that all other coefficients in Table 9 are stable with regard to the previous regression without investment (compare with Table 8). Further, and more relevant, note that investment is positively and significantly associated with productivity growth in the period 1991-95. In the second sub-period the evidence is more scant, and there is a quite large number of sectors for which investment does not seem to have a significant effect on growth in productivity.
A final consideration is however due. In most of the estimates discussed in this section, even when the coefficients of the right-hand-side variables are significant, the explanatory power of the model-in terms of the "explained" part of the variance, as captured by the $R^{2}$ statisticis rather low. This basically hints at the existence of firm-specific, highly idiosyncratic drivers of productivity growth which remain largely undetected. 
Table 10 Difference in difference regression. Standard errors in brackets

\begin{tabular}{|c|c|c|c|c|}
\hline & $\begin{array}{l}(1) \\
1996 / 2004 \\
\text { Level }\end{array}$ & $\begin{array}{l}\text { (2) } \\
\text { 1996-97/2003-04 } \\
\text { Level }\end{array}$ & $\begin{array}{l}(3) \\
\text { Fixed effect } \\
\text { Level }\end{array}$ & $\begin{array}{l}\text { (4) } \\
\text { 1996-98/2001-04 } \\
\text { Growth }\end{array}$ \\
\hline Post $*$ Exp & $\begin{array}{r}-\mathbf{0 . 0 6 2} \\
(0.016)\end{array}$ & $\begin{array}{r}-\mathbf{0 . 0 6 4} \\
(0.020)\end{array}$ & $\begin{array}{r}-\mathbf{0 . 0 1 8} \\
(0.008)\end{array}$ & $\begin{array}{r}-0.026 \\
(0.021)\end{array}$ \\
\hline Size & $\begin{array}{r}-\mathbf{0 . 0 6 7} \\
(0.016)\end{array}$ & $\begin{array}{r}-\mathbf{0 . 0 5 5} \\
(0.021)\end{array}$ & $\begin{array}{r}-\mathbf{0 . 1 4 9} \\
(0.011)\end{array}$ & $\begin{array}{c}\mathbf{0 . 0 5 1} \\
(0.019)\end{array}$ \\
\hline Pat & $\begin{array}{r}\mathbf{0 . 0 7 4} \\
(0.023)\end{array}$ & $\begin{array}{c}\mathbf{0 . 0 6 8} \\
(0.026)\end{array}$ & $\begin{array}{c}\mathbf{0 . 0 3 1} \\
(0.012)\end{array}$ & $\begin{array}{r}-0.026 \\
(0.028)\end{array}$ \\
\hline Observations & 7774 & 5160 & 50947 & 6735 \\
\hline$R$-squared & 0.006 & 0.006 & 0.76 & 0.002 \\
\hline
\end{tabular}

Coefficients significant at the $5 \%$ are in bold. Our elaboration on Micro.3

\subsection{The effect of export before and after the Euro}

Our previous analysis seems to suggest the existence of some differences in the effect of export on productivity growth before and after the occurrence of the Euro. In this section we further investigate this issue by specifying an econometric model that enables better identification of how productivity responds to export activity changes over time (Wooldridge 2002). The adoption of the common currency can be interpreted as an exogenous policy affecting the exporters (the treatment group), which now face greater competition, but not the firms serving the domestic market only (the control group). Thus, letting $T=2$ with $t=1$ for the pre-Euro and $t=2$ for the post-Euro period we estimate a difference in difference (DID) regression of the form:

$$
\begin{aligned}
y_{i, t}= & \alpha+\beta_{1} \text { post }_{t}+\beta_{2} \exp _{i}+\beta_{3} \exp _{i} * \text { post }_{t}+\beta_{4} Z_{i, t} \\
& +a_{i}+\varepsilon_{i, t} \\
t= & 1,2
\end{aligned}
$$

where $y_{i, t}$ denotes either firm's productivity level or growth at time $t$, post $t_{t}$ is a dummy variable for the post-Euro time period, the variable $\exp _{i}$ equals unity for exporters (i.e. those in the treatment group) and zero for non-exporters ${ }^{20}, Z_{i, t}$ is a vector of timevariant firm characteristics including size (log of total

\footnotetext{
${ }^{20}$ Note that we select in our dataset either those firms that have exported both before and after the adoption of the common currency, or those that have served the domestic market in both periods.
}

employment) and a patent dummy if a firm had any registered patents at time $t$, and $a_{i}$ is the firm fixed effect.

Subtracting to remove $a_{i}$ gives:

$\Delta y_{i}=\beta_{1}+\beta_{3} \Delta \exp _{i} *$ post $_{t}+\beta_{4} \Delta Z_{i}+\Delta \varepsilon_{i}$.

Therefore, the OLS estimator of $\beta_{3}$ in the subtracted equation measures the difference of the change in $y$ before and after the Euro between the treatment and the control groups. Columns (1) to (3) of Table 10 report the results using productivity level as dependent variable. In column (1) we estimate equation (7) using two years 1996 and 2004, for the pre and the post-Euro subperiods, respectively. ${ }^{21}$ In column (2) we use the average of each variable over 1996-97 for the first period and the average over 2003-04 for the second period. In column (3), we use all the years between 1996 and 2004 and we run the regression (equation 6) with firm fixed effects. Column (4) of Table 10 shows the results with productivity growth as predicted variable. The growth of productivity for the pre-Euro period is measured as the logarithmic differences between 1998 and 1996, and for the post-Euro period between 2004 and $2001 .^{22}$

\footnotetext{
$\overline{21}$ The validity of the DID estimator relies on the assumption that the underlying trends in the outcome variable is the same for both treatment and control groups. To check for this assumption we compare the trend of exporters and domestic firms in productivity (level and growth) in the pre-Euro years. In our case the common trend assumption of DID holds starting from 1996 onwards.

${ }^{22}$ Results do not change if different time intervals are used.
} 
The difference in difference approach shows that either the Euro does not have any apparent effect on productivity dynamics of exporters vs. non exporters or when it marginally does, puzzling enough, the difference in productivity between exporters and not seems to shrink slightly.

\subsection{Quantile regression analysis}

So far we have investigated the effects of a set of regressors on the growth rate of productivity via ordinary least squares (OLS). OLS models the effects exerted by a set of covariates on the conditional mean of the dependent variable. However, the covariates often affect the whole distribution of the dependent variable, not only the mean value (Koenker and Basset 1978; Koenker 2005). For instance we might observe that a change in the covariates may have opposite effects on the high and the low deciles of the dependent variables. In our case, for example, it might be that the productivity-enhancement effects of some covariates are different for low and high deciles. Given the significant and pervasive heterogeneities that have emerged in the analysis of the distribution of labor productivity and growth rates (discussed in Sect. 3), there are reasons to believe that such effects might be rather different for different deciles. In this section, we refine the analysis, and investigate which are the effects of the regressors at the different levels of the conditional distribution of the dependent variable, productivity growth.

Figures 5 and 6 report, for the first and second subperiods respectively, the results for some sectors which are quite illustrative of their generality. Each of the two figures displays at the top (bottom) the effects associated with investment (export) on different deciles of the conditional distribution of productivity growth.

The plots display a trend that is not detectable with OLS estimates, which are represented by the flat line. Thus, concerning investment in the first subperiod (top panel of Fig. 5), it seems that what one might call "return from investments" are higher for firms that have recorded higher productivity growth, meaning that investing in the first two years, 1991-92, has proved more beneficial for firms in the top decile of the conditional distribution of productivity growth. In the latter period, and focusing on export (bottom panel of Fig. 6), one notices that the effects of export activity at different deciles yield, for some levels of the conditional distribution, coefficients that are significantly different from zero. Further, we also observe that, with the exception of the chemical sector (NACE 24), exporting activity
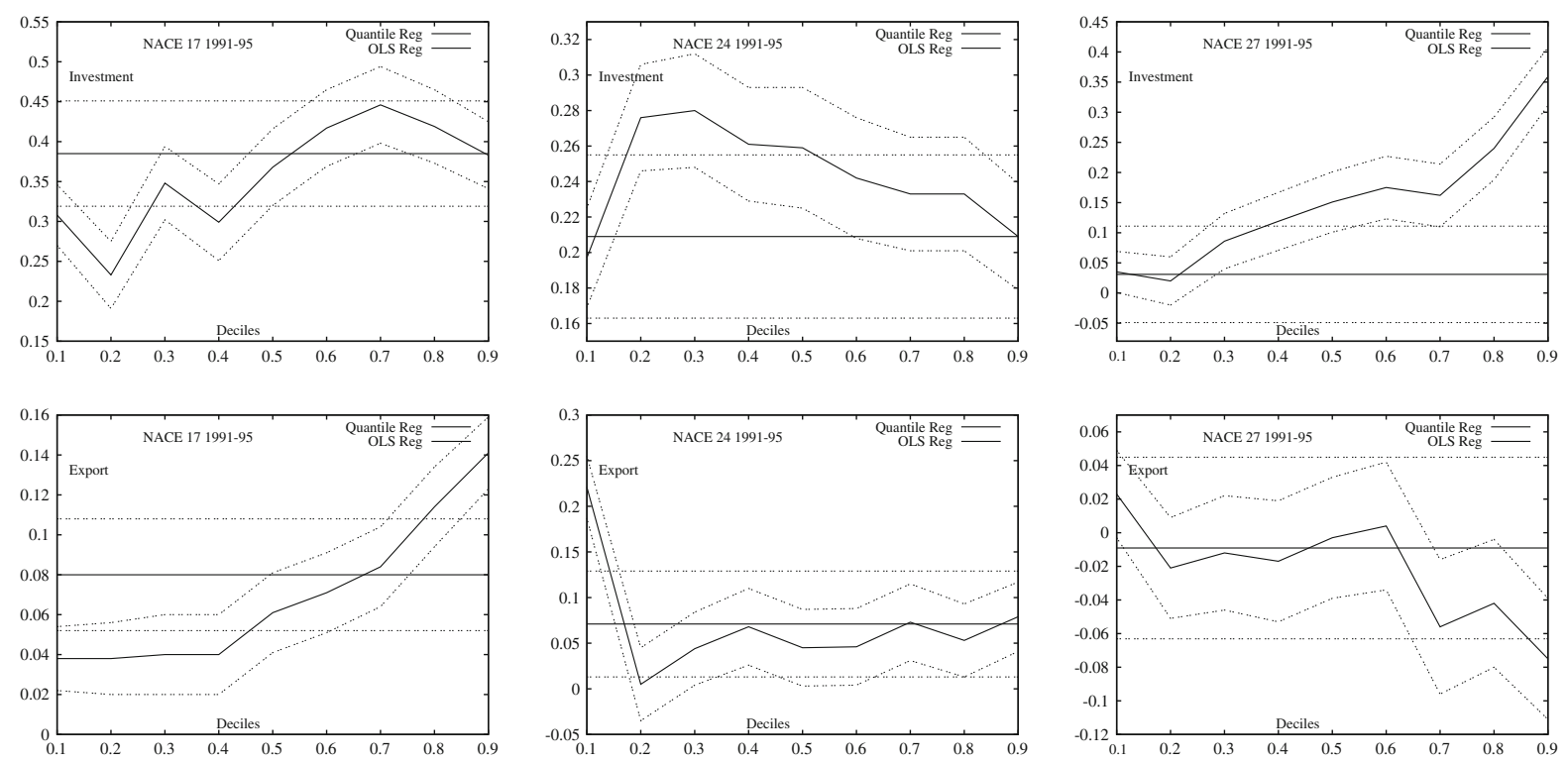

Fig. 5 Quantile regression estimates. Top The effect of investment on productivity growth in the first subperiod, 1991-95. Bottom The effect of export on productivity growth in the first subperiod, 1991-95. The error band (dashed lines) is of two standard errors 

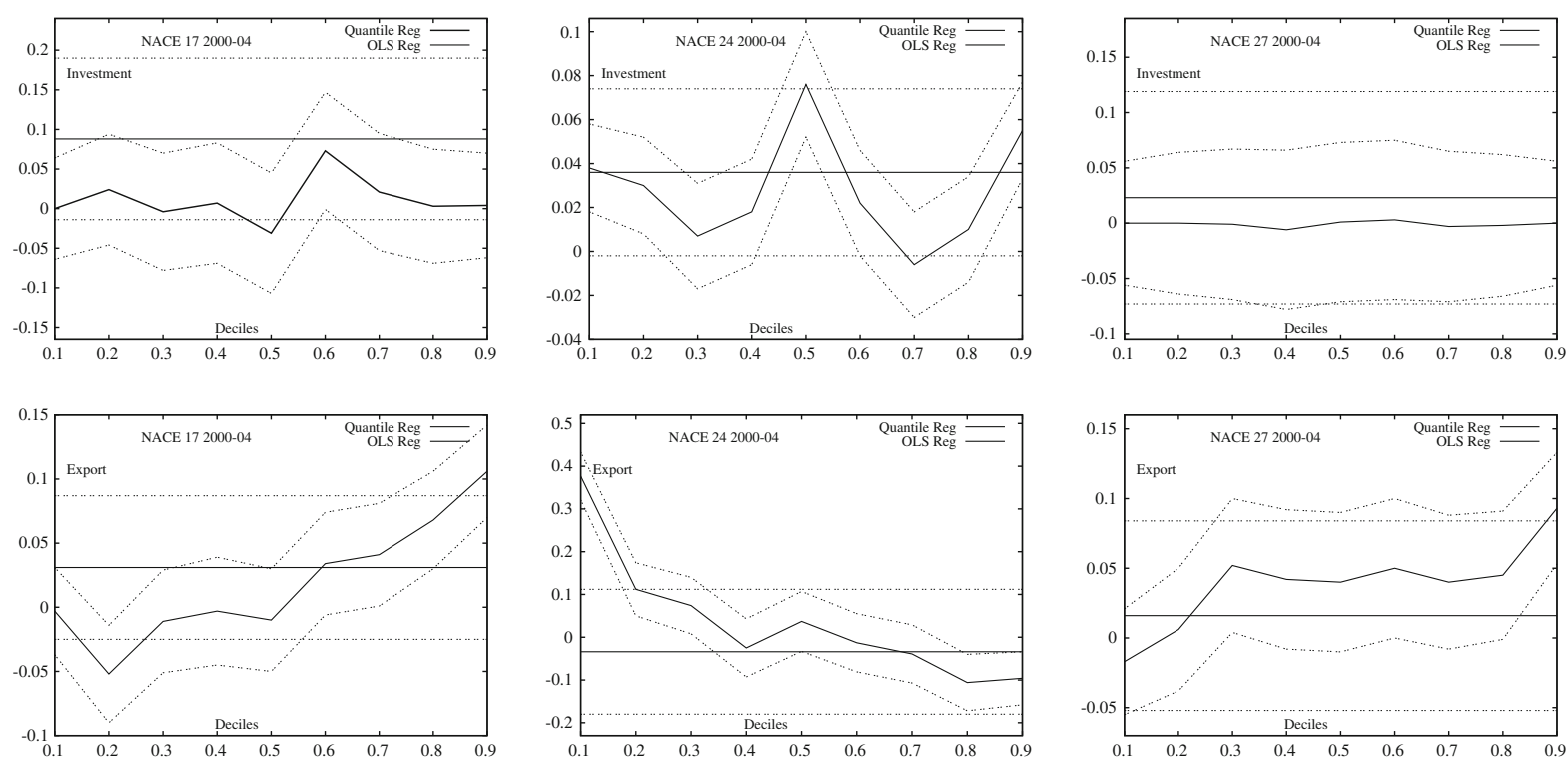

Fig. 6 Quantile regression estimates. Top The effect of investment on productivity growth in the second subperiod, 2000-04. Bottom The effect of export on productivity growth in the second subperiod, 2000-04. The error band (dashed lines) is of two standard errors

has been associated with higher productivity growth, especially for firms in the higher deciles of the conditional distribution.

Taken jointly, these two pieces of evidence suggest that, even during these two decades of low productivity growth, the effects associated to variables that may spur productivity are unevenly distributed among firms. In particular, the effects of export activity and investment on productivity growth turn out to be more pronounced, in particular among the group of high productivity growth firms. Such uneven distribution is, at least for some of the sectors, somewhat suggestive of the so-called "Matthew effect" in science (Merton 1968): "to those who have will be given, from those who have not will be taken away...". This also sheds some light on the sort of "low productivity trap" underlying the persistence of both low performance and high performance types identified above.

\section{Final remarks}

The micro longitudinal analysis in this work adds insights to diagnosis of the state of Italian manufacturing industry, but also has important implications for general understanding of the dynamics of industries, well beyond the Italian example.

Specifically for Italy, our data support a relatively bleak view of a manufacturing system which in general is locked in an industrial structure and in forms of organization that hinder expansion and productivity growth (a similar view is voiced by Banca d'Italia 2009 and Rossi 2009). Conversely, on first inspection our diagnosis sounds more pessimistic that the analyses put forward by MediobancaUnioncamere (2008) and Coltorti (2004) and also by Baldwin et al. (2007) and Lanza and Quintieri (2007), who all point from different angles at the existence of an ensemble of quite vital and dynamic firms able to successfully adjust to the "Euro shock" - successfully changing their product mix and able to seize new market and investment opportunities. The conflict, however, in our view is only apparent and is mainly based on sampleselection bias. So, for example, the Mediobanca sample considers a subset of firms of medium size which is likely to partly overlap with our "leader type" identified in the foregoing analysis. A significant ensemble of dynamic firms is certainly there and our analysis confirms it. However their number and size relative to the whole sector is not sufficient 
to push forward the overall performance indicators (in our case, sectoral labor productivity).

There are also patterns revealed by our data which might well be valid beyond the Italian boarder. One phenomenon that we see in the Italian data but may well be there also in other countries is the steady coexistence, again, of a group of dynamic firms with a generally bigger ensemble of much less technologically progressive firms which nonetheless survive quite comfortably, possibly exploiting local market niches. Let us call such pattern the tendency toward neo-dualism ${ }^{23}$ involving the steady co-existence of a quite large "laggard" part of any industry, even in relatively advanced economies.

The Italian experience concerning the selective effect of the Euro shock, or better, the lack of it, also adds further evidence to the general idea that markets do not do such a great job in relocating resources across firms characterized by different levels of efficiency (the point is analyzed at greater length by Bottazzi et al. 2010). If confirmed by comparable evidence from other countries, the conjectures on "neo-dualism" and on weak market selection, together, would offer a view of market competition and market dynamics somewhat less sanguine that the sturm und drang of Schumpeterian creative destruction.

Acknowledgments We benefitted from the comments of two anonymous referees and several participants in the conferences CAED 2009 Tokyo, ISS 2010 Aalborg, The Demography of firms and industries, Paris, and in particular John Sutton. We acknowledge financial support from the European Commission 6th FP (Contract CIT3-CT-2005- 513396), Project: DIMEDynamics of Institutions and Markets in Europe and from the
Institute for New Economic Thinking, INET inaugural grant $\# 220$. One of the authors (C.T.), gratefully acknowledges financial support by the Marie Curie Program Grant COFUND Provincia Autonoma di Trento "The Trentino Programme of research, training and mobility of post-doctoral researchers". The views expressed in the paper are those of the authors and not those of their respective institutions.

\section{Appendix A: Productivity levels and differences: three-digit analysis}

Table 11 reports the same analysis on the levels of productivity performed in Sect. 3.1 and focuses on three-digit sectors in order to verify if the aggregated analysis at the two-digit level introduced any bias in the results. This is not the case and results are coherent with the two-digit level analysis. Comparing the years 2004 and 2000, there are indeed 10 sectors (out of the 61 that fulfill the data requirements) in which productivity is higher in 2004 than in 1999. But there are six for which the reverse is true; and for all the other sectors the differences in the distribution of productivity in the two years is not significant.

Consider now year 2004 versus 1995. Productivity is higher in 2004 for 20 sectors. Yet for $2 / 3$ of our sample it is not possible to reject the null that the distribution of productivity has not shifted to the right. Thus, as it was for the analysis at the two-digit level (cf. Table 3), in order to recover some evidence of significantly different levels of productivity between two years, one has to compare the first and last year in the sample: in this case productivity is higher for most of sectors for which observations are available.

\footnotetext{
${ }^{23}$ The word "dualism" has been used historically to denote the co-existence of "modern" and "traditional" sectors, with, supposedly, the industrialization process fostering the expansion of the former and the progressive disappearance of the latter.
} 


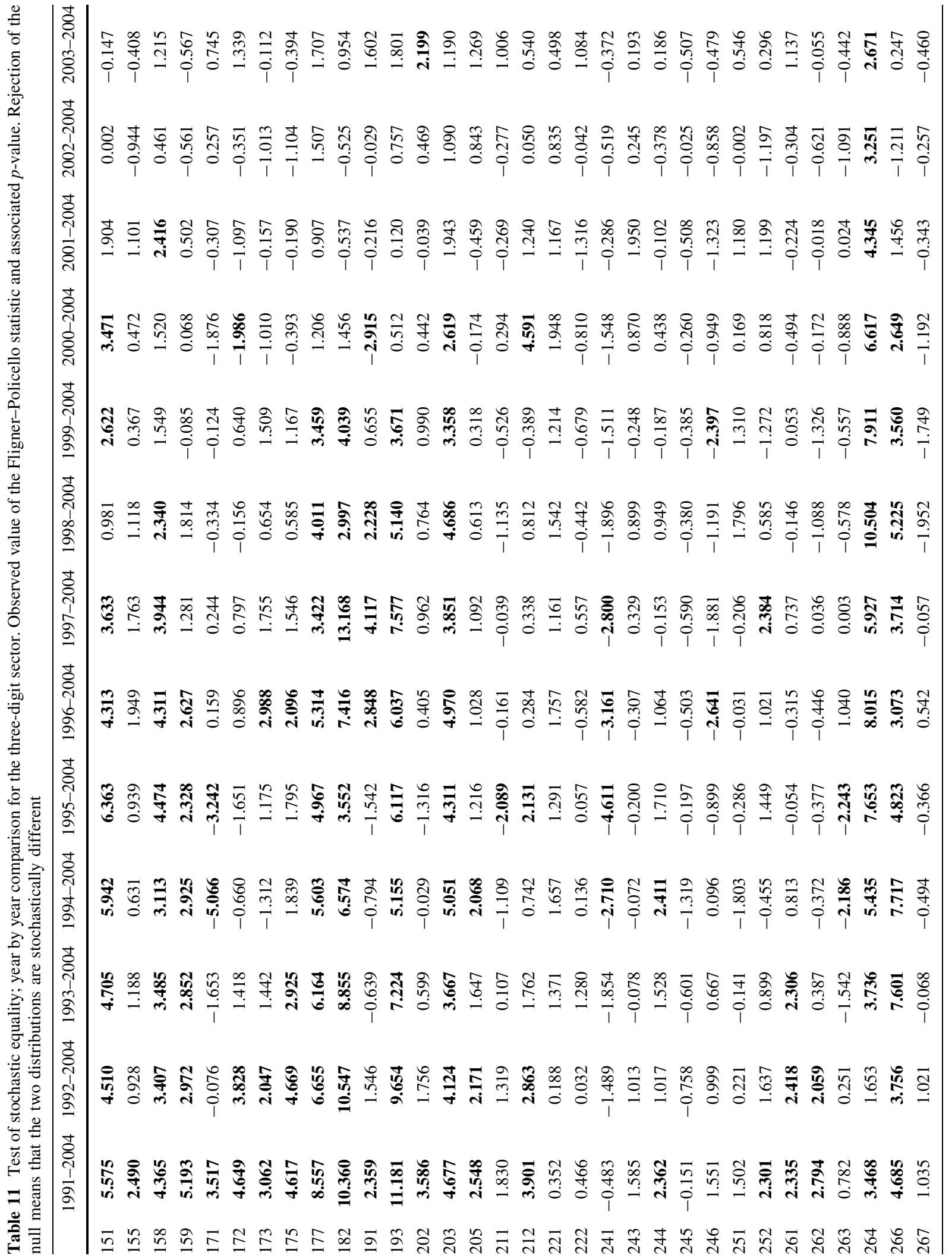




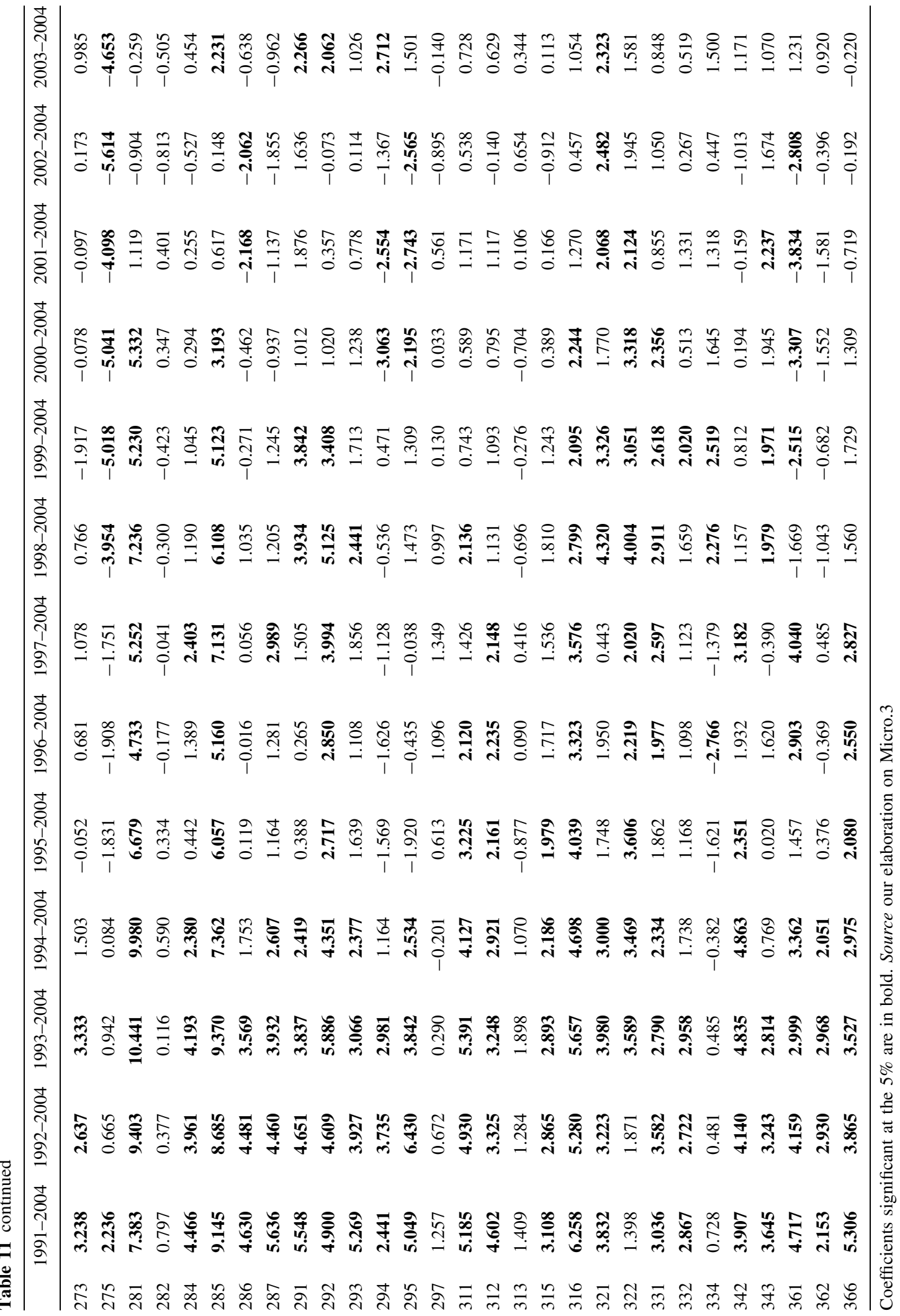




\section{Appendix B: Productivity growth by sector}

See Table 12.

Table 12 Growth of productivity regression. OLS estimates. Standard errors in brackets

\begin{tabular}{|c|c|c|c|c|c|c|c|c|}
\hline \multirow[t]{2}{*}{ Nace } & \multicolumn{4}{|c|}{ Productivity Growth 1991-95 } & \multicolumn{4}{|c|}{ Productivity Growth $2000-04$} \\
\hline & $\operatorname{Exp}_{t}$ & $\mathrm{Pat}_{t}$ & $L P_{t}$ & Size $_{t}$ & $\operatorname{Exp}_{t}$ & $\mathrm{Pat}_{t}$ & $L P_{t}$ & Size $_{t}$ \\
\hline \multirow[t]{2}{*}{15} & 0.032 & 0.057 & -0.203 & 0.007 & 0.040 & 0.154 & -0.211 & -0.005 \\
\hline & $(0.017)$ & $(0.066)$ & $(0.025)$ & $(0.008)$ & $(0.022)$ & $(0.052)$ & $(0.025)$ & $(0.013)$ \\
\hline \multirow[t]{2}{*}{17} & 0.066 & 0.109 & -0.186 & 0.015 & 0.053 & 0.062 & -0.220 & -0.024 \\
\hline & $(0.015)$ & $(0.090)$ & $(0.037)$ & $(0.008)$ & $(0.020)$ & $(0.051)$ & $(0.036)$ & $(0.012)$ \\
\hline \multirow[t]{2}{*}{18} & 0.057 & 0.000 & -0.143 & 0.029 & 0.109 & -0.142 & -0.167 & -0.011 \\
\hline & $(0.021)$ & $(0.000)$ & $(0.024)$ & $(0.011)$ & $(0.028)$ & $(0.089)$ & $(0.035)$ & $(0.021)$ \\
\hline \multirow[t]{2}{*}{19} & 0.006 & -0.074 & -0.235 & 0.061 & 0.024 & -0.060 & -0.194 & 0.027 \\
\hline & $(0.026)$ & $(0.072)$ & $(0.051)$ & $(0.015)$ & $(0.031)$ & $(0.081)$ & $(0.037)$ & $(0.017)$ \\
\hline \multirow[t]{2}{*}{20} & 0.058 & 0.089 & -0.197 & 0.063 & -0.008 & 0.107 & -0.296 & 0.052 \\
\hline & $(0.026)$ & $(0.076)$ & $(0.050)$ & $(0.020)$ & $(0.030)$ & $(0.072)$ & $(0.054)$ & (0.024) \\
\hline \multirow[t]{2}{*}{21} & 0.042 & 0.076 & -0.194 & 0.039 & -0.018 & 0.083 & -0.245 & 0.034 \\
\hline & $(0.031)$ & $(0.095)$ & $(0.089)$ & $(0.023)$ & $(0.026)$ & $(0.062)$ & $(0.035)$ & $(0.018)$ \\
\hline \multirow[t]{2}{*}{22} & -0.010 & 0.087 & -0.259 & 0.055 & -0.050 & -0.087 & -0.280 & 0.106 \\
\hline & $(0.024)$ & (0.189) & $(0.068)$ & $(0.019)$ & $(0.026)$ & $(0.079)$ & $(0.135)$ & $(0.026)$ \\
\hline \multirow[t]{2}{*}{24} & 0.059 & 0.037 & -0.288 & 0.028 & -0.009 & -0.020 & -0.265 & -0.003 \\
\hline & $(0.028)$ & (0.049) & $(0.069)$ & $(0.013)$ & $(0.042)$ & $(0.032)$ & (0.037) & $(0.013)$ \\
\hline \multirow[t]{2}{*}{25} & -0.020 & 0.085 & $-\mathbf{0 . 1 7 7}$ & 0.045 & 0.012 & 0.028 & $-\mathbf{0 . 1 7 0}$ & 0.018 \\
\hline & $(0.018)$ & $(0.047)$ & $(0.037)$ & $(0.009)$ & $(0.020)$ & $(0.021)$ & $(0.026)$ & (0.008) \\
\hline \multirow[t]{2}{*}{26} & 0.096 & 0.147 & -0.140 & -0.002 & -0.129 & -0.077 & -0.321 & 0.062 \\
\hline & $(0.029)$ & $(0.131)$ & $(0.072)$ & $(0.020)$ & $(0.122)$ & $(0.067)$ & $(0.052)$ & $(0.017)$ \\
\hline \multirow[t]{2}{*}{27} & -0.059 & -0.089 & -0.281 & 0.021 & 0.038 & 0.066 & -0.174 & -0.001 \\
\hline & $(0.036)$ & $(0.095)$ & (0.104) & (0.019) & $(0.029)$ & $(0.057)$ & $(0.060)$ & $(0.015)$ \\
\hline \multirow[t]{2}{*}{28} & 0.055 & 0.059 & -0.246 & 0.024 & 0.015 & 0.049 & -0.233 & 0.024 \\
\hline & $(0.012)$ & $(0.042)$ & $(0.024)$ & (0.009) & $(0.008)$ & $(0.022)$ & (0.019) & (0.007) \\
\hline \multirow[t]{2}{*}{29} & 0.025 & 0.101 & -0.295 & 0.026 & 0.026 & 0.028 & -0.317 & 0.018 \\
\hline & $(0.011)$ & $(0.021)$ & $(0.029)$ & $(0.006)$ & $(0.017)$ & $(0.014)$ & $(0.041)$ & $(0.006)$ \\
\hline \multirow[t]{2}{*}{31} & 0.065 & 0.087 & -0.207 & 0.039 & 0.068 & 0.019 & -0.185 & -0.002 \\
\hline & $(0.022)$ & $(0.041)$ & $(0.032)$ & $(0.009)$ & $(0.035)$ & $(0.031)$ & $(0.034)$ & (0.017) \\
\hline \multirow[t]{2}{*}{32} & 0.080 & 0.136 & -0.507 & 0.013 & 0.039 & 0.174 & -0.252 & 0.071 \\
\hline & $(0.055)$ & (0.139) & $(0.157)$ & $(0.018)$ & $(0.051)$ & $(0.082)$ & $(0.075)$ & $(0.034)$ \\
\hline \multirow[t]{2}{*}{33} & 0.061 & 0.082 & -0.155 & 0.001 & 0.113 & 0.009 & -0.291 & 0.029 \\
\hline & $(0.037)$ & $(0.043)$ & $(0.057)$ & $(0.021)$ & $(0.042)$ & $(0.036)$ & $(0.039)$ & $(0.015)$ \\
\hline \multirow[t]{2}{*}{34} & 0.039 & -0.004 & -0.081 & -0.025 & 0.056 & 0.036 & -0.295 & 0.005 \\
\hline & $(0.056)$ & $(0.108)$ & $(0.116)$ & $(0.026)$ & $(0.048)$ & $(0.040)$ & $(0.086)$ & $(0.015)$ \\
\hline \multirow[t]{2}{*}{35} & 0.199 & 0.258 & 0.140 & 0.003 & 0.023 & 0.094 & -0.388 & 0.020 \\
\hline & $(0.167)$ & (0.193) & $(0.253)$ & $(0.107)$ & $(0.051)$ & $(0.079)$ & $(0.080)$ & $(0.026)$ \\
\hline \multirow[t]{2}{*}{36} & 0.047 & 0.017 & -0.253 & 0.046 & 0.029 & 0.057 & -0.265 & 0.040 \\
\hline & $(0.017)$ & $(0.055)$ & $(0.038)$ & $(0.012)$ & $(0.024)$ & $(0.032)$ & $(0.031)$ & $(0.012)$ \\
\hline
\end{tabular}

Coefficients significant at the $5 \%$ are in bold. Source our elaboration on Micro.3 


\section{References}

Aw, B. Y., Roberts, M. J., \& Xu, D. Y. (2008). R\&D investments, exporting, and the evolution of firm productivity. American Economic Review, 98(2), 451-56.

Baily, M. N., Hulten, C., \& Campbell, D. (1992). Productivity dynamics in manufacturing establishments. Brookings Papers on Economic Activity: Microeconomics, 4, 187-249.

Baldwin, R., Barba Navaretti, G., \& Boeri, T. (2007). Come sta cambiando l'Italia, Bologna: Il Mulino.

Banca d'Italia (2009). Rapporto sulle tendenze nel sistema produttivo italiano, Questioni di economia e finanza 45, Banca d'Italia.

Bartelsman, E. J., \& Dhrymes, P. J. (1998). Productivity dynamics: U.S. manufacturing plants, 1972-1986. Journal of Productivity Analysis, 9(1), 5-34.

Bartelsman, E. J., \& Doms, M. (2000). Understanding productivity: Lessons from longitudinal microdata. Journal of Economic Literature, 38(2), 569-594.

Bernard, A. B., \& Jensen, B. J. (1995). Exporters, jobs, and wages in US manufacturing: 1976-87. Brookings Papers on Economic Activity: Microeconomics, 1995, 67-112.

Bernard, A. B., \& Jensen, B. J. (1999). Exceptional exporter performance: Cause, effect, or both? Journal of International Economics, 47(1), 1-25.

Bottazzi, G., Cefis, E., Dosi, G., \& Secchi, A. (2007). Invariances and diversities in the evolution of Italian manufacturing industry. Small Business Economics, 29(1-2), 137-159.

Bottazzi, G., Dosi, G., Jacoby, N., Secchi, A., \& Tamagni, F. (2010). Corporate performances and market selection. some comparative evidence, Industrial and Corporate Change, 19(6), 1953-1996. forthcoming.

Bottazzi, G., \& Grazzi, M. (2010). Wage-size relation and the structure of work-force composition in italian manufacturing firms. Cambridge Journal of Economics, 34(4), 649-669.

Bottazzi, G., Grazzi, M., \& Secchi, A. (2005). Input output scaling relations in Italian manufacturing firms. Physica A, 355, 95-102.

Bottazzi, G., \& Secchi, A. (forthcoming). Maximum likelihood estimation of the symmetric and asymmetric exponential power distribution, Industrial and Corporate Change.

Bugamelli, M., Schivardi, F., \& Zizza, R. (2010). The euro and firm restructuring. Europe and the Euro, NBER Chapters, National Bureau of Economic Research, pp. 99-138.

Castellani, D., \& Zanfei, A. (2007). Internationalisation, innovation and productivity: How do firms differ in Italy? The World Economy, 30(1), 156-176.

Clerides, S. K., Lach, S., \& Tybout, J. R. (1998). Is learning by exporting important? micro-dynamic evidence from Colombia, Mexico, and Morocco. The Quarterly Journal of Economics, 113(3), 903-947.

Coltorti, F. (2004). Le medie imprese industriali italiane: nuovi aspetti economici e finanziari. Economia e Politica Industriale, 121, 2-25.

Davis, S. J., Haltiwanger, J. C., \& Schuh, S. (1996). Job creation and destruction. Cambridge, MA: MIT Press.

Dosi, G., Faillo, M., \& Marengo, L. (2008). Organizational capabilities, patterns of knowledge accumulation and governance structures in business firms: an introduction. Organization Studies, 29, 1165-1185.

Dosi, G., \& Grazzi, M. (2006). Technologies as problemsolving procedures and technologies as input-output relations: Some perspectives on the theory of production. Industrial and Corporate Change, 15(1), 173-202.

Dosi, G., Nelson, R. R., \& Winter, S. (Eds.). (2000). The nature and dynamics of organizational capabilities. Oxford: Oxford University Press.

Dunne, T. (1994). Plant age and technology use in U.S. manufacturing industries. RAND Journal of Economics, 25(3), 488-499.

Dunne, T., Roberts, M. J., \& Samuelson, L. (1988). Patterns of firm entry and exit in U.S. manufacturing industries. Rand Journal of Economics, 19, 495-515.

Dunne, T., Roberts, M. J., \& Samuelson, L. (1989). The growth and failure of U.S. manufacturing plants. The Quarterly Journal of Economics, 104(4), 671-98.

Fligner, M. A., \& Policello, G. E. (1981). Robust rank procedures for the Behrens-Fisher problem. Journal of the American Statistical Association, 76(373), 141-206.

Foster, L., Haltiwanger, J., \& Syverson, C. (2008). Reallocation, firm turnover, and efficiency: Selection on productivity or profitability?. American Economic Review, 98(1), 394-425.

Grazzi, M. (2009). Trade and profitability: Is there an export premium? Evidence from Italian manufacturing firms, LEM Papers Series 2009/16, Laboratory of Economics and Management (LEM), Sant'Anna School of Advanced Studies, Pisa, Italy.

Grazzi, M., Sanzo, R., Secchi, A., \& Zeli, A. (2009). Micro.3 some notes on the development of the integrated system of data 1989-2004, Documenti n. 11, Istat.

Hall, B. H., \& Mairesse, J. (1995). Exploring the relationship between R\&D and productivity in french manufacturing firms. Journal of Econometrics, 65(1), 263-293.

Haltiwanger, J. C., Lane, J. I., \& Spletzer, J. R. (1999). Productivity differences across employers: The roles of employer size, age, and human capital. American Economic Review, 89(2), 94-98.

Koenker, R. (2005). Quantile regression, Cambridge: Cambridge University Press.

Koenker, R., \& Basset, G. W. (1978). Regression quantiles. Econometrica, 46, 33-50.

Lanza, A., \& Quintieri, B. (Eds) (2007). Eppur si muove. Come cambia l'export italiano. Soveria Mannelli: Rubbettino.

Lilien, D. (1982). Sectoral shifts and cyclical unemployment. Journal of Political Economy, 90, 773-793.

Mediobanca-Unioncamere (2008). Le medie imprese industriali italiane (1996-2005), Technical report, MediobancaUnioncamere. http://www.mbres.it.

Merton, R. K. (1968). The matthew effect in science. Science, 159(3810), 56-63.

OECD. (2008). Compendium of productivity indicators. Cedex, France: OECD Publishing.

Pavitt, K. (1984). Sectoral pattern of technical change: Towards a taxonomy and a theory. Research Policy, 13, 343-373.

Roberts, M. J., \& Tybout, J. R. (1997). The decision to export in colombia: An empirical model of entry with sunk costs. American Economic Review, 87(4), 545-64. 
Rossi, S. (2009). Controtempo. L'Italia nella crisi mondiale. Bari: Laterza.

Serti, F., \& Tomasi, C. (2008). Self-selection and post-entry effects of exports: Evidence from Italian manufacturing firms. Review of World Economics (Weltwirtschaftliches Archiv), 144(4), 660-694.

Subbotin, M. F. (1923). On the law of frequency of errors. Matematicheskii Sbornik, 31, 296-301.

Teece, D. J., Rumelt, R., Dosi, G., \& Winter, S. (1994). Understanding corporate coherence: Theory and evidence.
Journal of Economic Behavior \& Organization, 23(1), $1-30$.

Winter, S. G. (1987). Knowledge and competences as strategic assets. In D. J. Teece (Eds.), The competitive challenge: Strategy and organization for Industrial Innovation and renewal. Cambridge, MA: Ballinger.

Wooldridge, J. M. (2002). Econometric analysis of cross section and panel data. Cambridge, MA: The MIT Press. 